\title{
Oxidation Behavior in Reaction-Bonded \\ Aluminum-Silicon Alloy/Alumina Powder Compacts
}

by

Shari Hanayo Yokota

(M.S. Thesis)

Department of Materials Science and Mineral Engineering, University of California at Berkeley

and

Materials Sciences Division

Lawrence Berkeley Laboratory

University of California

Berkeley, California 94720

\section{December 1992}


Table of Contents

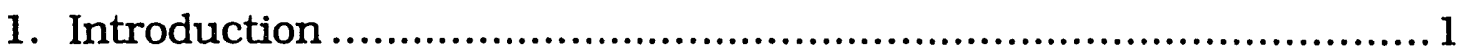

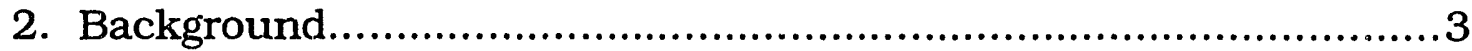

2-1. Reaction-Bonded Materials ......................................... 3

2-2. Directed Melt Oxidation ...............................................4

2-3. Reaction-Bonded Alumina Systems ................................. 7

2-3-1. Reaction-Bonded Alumina ................................

2-3-2. Reaction-Bonded Mullite ................................. 11

3. Experimental Procedure .................................................... 12

3-1. Materials Selection................................................. 12

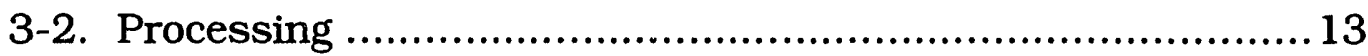

3-3. Heat Treatment..................................................... 14

3-4. Characterization ...................................................... 14

3-4-1. Microstructure and Reaction Rings.......................15

3-4-2. Compositional Analysis ....................................15

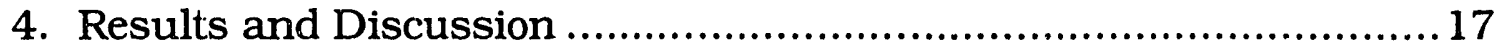

4-1. Reaction Rings and Microstructure .............................. 17

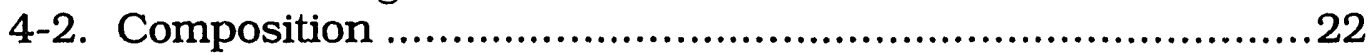

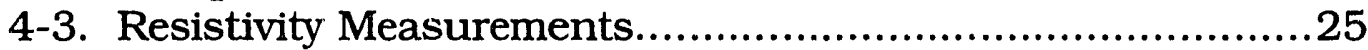

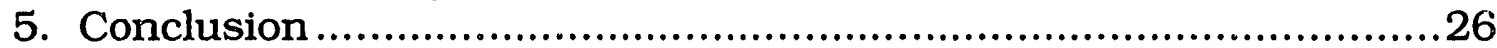

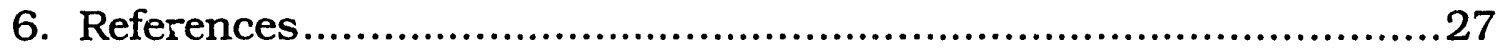

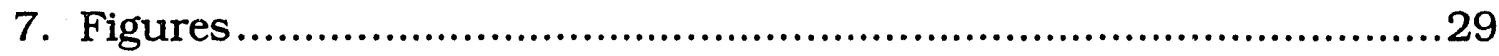




\section{Introduction}

Reaction-formed or reaction-bonded materials, such as $\mathrm{Si}_{3} \mathrm{~N}_{4}$ and $\mathrm{SiC}$, are formed from a solid material which increases in mass during high temperature reaction with either a gas or a liquid. Reaction forming processes permit, in principle, near net-shape production of complex shapes; thus, the ceramic industry finds the technique attractive because current forming techniques often require expensive machining of hard and brittle sintered ceramic materials. In addition to raising manufacturing costs, the final machining step can introduce critical surface flaws which reduce the fracture strength of the product. Applications for alumina and alumina-based ceramics include electronic packaging and bioceramic products which have tight dimensional tolerances. ${ }^{1}$ Using conventional powder processing technology, ceramic manufacturers must ascommodate volume shrinkages of 15 percent, or greater, between the green body and the sintered alumina product. ${ }^{2} \mathrm{~A}$ near net-shape process for sintered alumina would allow manufacturers to produce strong ceramic bodies with complex shapes at low cost.

The reaction-bonding process proposed by Claussen, et al., starts by vigorously milling together aluminum and ceramic powders. The comminuted powders are then compacted into desired shapes and heat treated. Low-shrinkage ceramics are produced by countering the sintering shrinkage of the compact with the volume expansion accompanying oxidation of the metal phase. ${ }^{3}$ In theory, this process could be applied to any metal/oxide system in which the metal-to-oxide volume increase is at least equal to the pore space in the green body. 
The goal of this research is to determine the feasibility of producing low-shrinkage mullite/alumina composites by applying the reactionbonded alumina (RBAO) process to an aluminum-silicon alloy/alumina system. Microstructural and compositional changes during heat treatment were studied by removing samples from the furnace at different steps in the heating schedule and then using optical and scanning electron microscopy, EDS and XRD to characterize the powder compacts. The results suggest that the oxidation behavior of the alloy compact is different from the model proposed for the pure $\mathrm{Al}$ /alumina system. 


\section{Background}

\section{2-1. Reaction-Bonded Materials}

The traditional ceramic processing method of sintering powder compacts results in the formation of new phases (mullite for example) or of necks between particles, but does not involve a mass change for the body as a whole. Thus, mass transport in traditional ceramics is on the order of the particle size and does not restrict the size of the body. However, manufacturers of sintered alumina bodies must accommodate 12 15\% linear shrinkage (35\% volume shrinkage) which, aside from the aforementioned final machining step, can induce severe stresses which may warp complex or thin shapes. 4,5

Unlike traditionally sintered materials, the components of reactionformed ceramics must come from outside the initial body. Thus, mass transport in these materials occurs over distances on the order of the initial piece and the ultimate size of reaction-formed ceramic bodies is limited by considerations of the kinetics of mass transport and heat transfer.

Reaction-forming processes can, in principle, be combined with sintering to produce near net-shape ceramic bodies. Reaction-bonded silicon nitride (RBSN) is perhaps the most well-known example of this type of material. A typical RBSN fabrication procedure involves presintering a silicon powder compact, machining the piece, and finally reacting the $\mathrm{Si}$ in a nitrogen atmosphere at $1250{ }^{\circ} \mathrm{C}$ to $1450{ }^{\circ} \mathrm{C}$. Alternatively, the piece could be shaped directly by slip-casting, 
extrusion, injection-molding, etc., before reaction-bonding. The resulting ceramic has a porosity of approximately 20 volume percent; however, the pores are very fine ( 80 percent are less than $0.1 \mu \mathrm{m}$ ) and the fully reacted piece undergoes a size change of about $0.1 \%{ }^{6}$ The high residual porosity is a result of the need to maintain a continuous pore structure in order to diffuse the nitrogen into the center of the body.

Several research groups have been applying reaction-forming and reaction-bonding techniques to the alumina system $3,7,8$ and to the alumina/mullite system.9, 10, 11, 12 Two approaches incorporate a metal phase in the initial piece--the directed melt oxidation (DMO or DIMOX) process and the RBAO process. The DMO process, although distinct from the RBAO process, also takes advantage of the unique properties imparted to the final piece by the oxidation of the metal phase. A brief description of each process follows.

\section{2-2. Directed Melt Oxidation}

In the DMO process, an aluminum alloy (<10 wt.\% each $\mathrm{Mg}, \mathrm{Si}, \mathrm{Zn}$ ) is cast in the desired shape which is then embedded in alumina grains $\left(\sim 100\right.$ mesh) and oxidized at temperatures as low as $1400{ }^{\circ} \mathrm{C}$. Unlike RBSN fabrication in which the preform's initial particle size and green body density are critical process variables, the microstructure of the DMO preform is relatively unimportant. The preform melts as it is heated above the alloy's melting temperature. Following an incubation period, the duration of which varies with processing conditions, an oxide layer grows outward from the surface of the molten alloy and forms a strong interconnected structure containing isclated pockets of $\mathrm{Al}$ alloy. 
The relative amounts of each phase can be controlled by the composition of the initial alloy and by the heating schedule. A recently developed variation of the process is closer to the reaction-bonded SiC paradigm because it uses a porous ceramic preform which is infiltrated by the molten alloy. 8

Microstructural characterization of DMO composites shows that during oxidation the reaction product is riddled with microchannels, perpendicular to the molten metal/oxide interface, through which the alloy is "wicked" toward the oxide/gas phase interface. As the alloy reservoir is consumed, the channels seal off and leave the pockets of unreacted metal that are observed in the finished material. Despite the residual metal phase, the composite retains its strength at high temperatures because the grain boundaries in the interconnected alumina phase are free of any low melting-point glassy phase. ${ }^{13}$ Since the reaction mechanism involves movement of the low viscosity melt toward the gas phase interface, the ultimate thickness of pieces formed by this process is limited by the height to which capillary force could draw a column of molten alloy. The height, $h$, is given by

$$
h=\frac{2 \gamma \cos \theta}{\rho g r}
$$

where $\gamma=$ surface tension $(815 \mathrm{mN} / \mathrm{m}), \rho=$ density of the liquid (estimate at $2.7 \mathrm{~g} / \mathrm{cc}), g=$ acceleration of gravity $\left(9.8 \mathrm{~m} / \mathrm{s}^{2}\right)$ and $\theta=$ wetting angle. Assuming complete wetting of the oxide by the alloy (i.e., there is no oxide skin to inhibit wetting), and a microchannel radius of 5 $\mu \mathrm{m}, 8 \mathrm{~h}$ could reach a maximum value of $\sim 12 \mathrm{~m}$. Composites $10 \mathrm{~cm}$ thick, grown with no indication of a decrease in growth rate have been reported. ${ }^{7}$ 
The microchannels may be the prim ary mechanism by which bulk oxidation occurs; however, the early stages of oxidation would be more likely to resemble the oxidation behavior of the metal particles in a powder compact. The bulk oxidation is preceded by an incubation period during which the $\mathrm{Mg}$ in the alloy is evaporated at the surface of the silvery melt and re-deposited as a thin layer ( $<1 \mu \mathrm{m}$ thick) of MgO. In addition, a $\mathrm{MgAl}_{2} \mathrm{O}_{4}$ layer, interspersed with metallic $\mathrm{Al}$ and $\mathrm{Si}$, forms between the melt and the surface MgO; the microchannel phenomenon is first observed in this spinel layer. The $\mathrm{MgO}-\mathrm{MgAl}_{2} \mathrm{O}_{4}$ double layer causes the originally silvery surface of the melt to appear dark gray. 8,14 The underside of the MgO layer is reduced by the molten metal brought up through the microchannels. The oxide layer is thus extended while the $\mathrm{Mg}^{2+}$ cation diffuses back through the $\mathrm{MgO}$ layer to react with oxygen at the surface. Si, which is also found at the interface, may help to decrease the activity of the $\mathrm{Mg}$ (possibly through the formation of $\mathrm{Mg}_{2} \mathrm{Si}$ ), thus preventing the recombination of $\mathrm{Mg}^{2+}$ and $\mathrm{O}=$ on the underside of the MgO layer. ${ }^{8}$ Near the end of this incubation period, the MgO layer thins and the microchannels puncture the surface oxide to form $\mathrm{Al} / \mathrm{Al}_{2} \mathrm{O}_{3}$ nodules on the surface (See Fig. 1). This marks the start of the bulk oxidation as the microchannel structure is apparently self-perpetuating. The spinel layer remains near the metal-oxide interface for the duration of the reaction. It is believed to supply the oxygen that closes off the microchannels and forms the pockets of $\mathrm{Al}_{1}$ alloy when the last of the molten metal reservoir has been drawn up into the channels. 


\section{2-3. Reaction-Bonded Alumina Systems}

Several process parameters are common to both RBAO and reaction-bonded mullite fabrication. First is particle size; the metal particles must be sufficiently fine $(\sim 1 \mu \mathrm{m})$ to ensure complete reaction with the gas phase within a reasonable period of time. However, if the particles are too small, the smaller pore size could reduce gas diffusion rates, and the higher surface energy could lead to premature sintering of the ceramic particles. Second is green body density; the initial density must be low enough (about $70 \%$ of theoretical density) to provide continuous porosity through which the reactant gas can reach the center of the sample. Third is heating rate; the heating schedule must also be carefully controlled to prevent sintering near the surface of the body prior to complete reaction of the material in the core of the piece. The primary difference between RBAO and reaction-bonded mullite is in the chemistry of the metal-to-oxide reactions. The RBAO process is described below, followed by a section describing the unique aspects of mullite fabrication.

\section{2-3-1. Reaction-Bonded Alumina}

The RBAO process as developed by Claussen, et al., involves the reaction of a powder compact with a gas phase. $40 \sim 50$ volume percent $\mathrm{Al}, 40 \sim 50$ volume percent $\mathrm{Al}_{2} \mathrm{O}_{3}$ and $0 \sim 10$ volume percent $\mathrm{ZrO}_{2}$ particles are vigorously milled together until the oxide particle size is reduced to 1 $\mu \mathrm{m}$ or less. The powder is then cold-isostatically pressed to approximately $70 \%$ of theoretical density. The high proportion of metal in the compact renders the green body relatively easy to machine before it is converted to hard and brittle sintered alumina. The compact is then 
heated in air, using a two stage schedule that features an extended hold at $800 \sim 1150^{\circ} \mathrm{C}$ to oxidize the metal followed by a shorter hold at $1400 \sim 1500{ }^{\circ} \mathrm{C}$ to sinter the material. The resulting specimen contains no residual metal, has a final density that is about $93 \%$ of theoretical, and it has undergone about $2 \%$ linear shrinkage. Despite the residual porosity, mechanical strengths comparable to that of conventionally sintered alumina, $300 \mathrm{MPa}$, have been reported. The high strength is attributed to the fine particle size of the initial materials. ${ }^{9} 98 \%$ dense material has been produced, however the higher density is accompanied by greater shrinkage between the green compact and the sintered body. ${ }^{3}$

Claussen, et al., propose the following mechanism for the oxidation of the compact. ${ }^{2}$ During the milling process, submicron oxide particles are worked into the metal flakes and a thin oxide skin forms on the metal particles. The oxide skin makes the metal powder safe to handle and it inhibits wetting of the original oxide particles despite heating above the $\mathrm{Al}$ melting point $\left(660^{\circ} \mathrm{C}\right)$. As the compact is heated through the melting point, little particle rearrangement or compaction, characteristic of liquid phase sintering, is observed. 15,16 The volume change accompanying the oxidation of the metal phase pushes the original ceramic particles apart and the compact experiences a linear expansion of $1 \sim 2 \%$. During the hold of eight hours or longer below $1150{ }^{\circ} \mathrm{C}$ the molten metal bursts through the oxide skin and flows into the pore spaces of the sample where it is oxidized. ${ }^{17}$ Finally, the compact is heated above $1200{ }^{\circ} \mathrm{C}$ to sinter the newly formed oxide and the original oxide grains. As the oxidation and sintering processes progress, the original oxygen diffusion path through connected porosity is pinched off. However, both the large number of grain boundaries and the $\mathrm{ZrO}_{2}$ particles provide high oxygen 
diffusion rate paths compared to bulk alumina. ${ }^{18}$ Figure 2 shows schematically the oxidation mechanisms described by Claussen, et al. The $\mathrm{ZrO}_{2}$ has the added benefit of increasing the toughness of the final alumina body. 19,20 During the sintering step, the compact undergoes a linear shrinkage of $2 \sim 3 \%$ for a net linear shrinkage of about $2 \%$.

Unlike the DMO process, there are no spinel formers, such as $\mathrm{Mg}$, added to the aluminum; therefore, microchannels are probably not the mechanism for causing the molten $\mathrm{Al}$ to rupture the passivation layer. Claussen, et al., propose that heating the molten metal within the constraints of the particle's oxide skin generates pressure sufficient to rupture the usually passivating layer and force the liquid metal into the pores. Published TGA data indicate that oxidation of the metal phase, as indicated by percent weight change, is more than $90 \%$ complete prior to the start of sintering. If the Claussen model is correct, fresh molten $\mathrm{Al}$ is constantly brought to the surface of the passivated grain. Therefore, the oxidation rate of the compact is a function of the diffusion rate of oxygen through the pores of a reacting compact rather than a function of the oxidation rate of the Al metal through a passivation layer. Szekely, Evans and Sohn discuss this extreme case where the rate of reaction in a porous compact is controlled by pore diffusion. ${ }^{21}$ For an oxidation reaction such as the one given below,

$$
\mathrm{aA}_{(\mathrm{g})}+\mathrm{bB}_{(\mathrm{s})} \rightarrow \mathrm{cC}_{(\mathrm{g})}+\mathrm{dD}_{(\mathrm{s})}
$$

the time to completion of the reaction, $t$, of a spherical pellet is given by the following equation, 


$$
t=\left(\left\{\left[2 b F_{p} D_{e}\left(C_{A 0}-\frac{C_{C 0}}{K_{E}}\right)\right] \div\left[(1-\varepsilon) \rho_{s}\left(\frac{F_{p} V_{p}}{A_{p}}\right)^{2}\right]\right\}\left\{\frac{K_{E}}{1+K_{E}}\right]\right)^{-1}
$$

Where $b=$ the stoichiometric coefficient in the chemical equation above, $F_{p}=$ shape factor ( 3 for spheres), $D_{e}=$ effective diffusivity in the pellet, $\mathrm{C}_{i o}$ = concentration of gas $i$ in the bulk gas stream, $K_{E}=$ equilibrium constant of the reaction, $\varepsilon=$ initial porosity plus volume fraction of inert solids, $\rho_{s}=$ molar concentration of solid reactant, $V_{p}=$ volume of pellet, and $A_{p}=$ surface area of pellet. $D_{e}$ for oxygen in air, $D_{O_{2} \text {-air.eff }}$, can be approximated using the following equation,

$$
D_{O_{2}-\text { air,eff }}=\frac{D_{\mathrm{O}_{2} \text {-air }} \omega}{\tau}
$$

where $\omega=$ void fraction of the solid, and $\tau=$ the tortuosity (assume $\tau=7$ ). An approximate maximum pellet diameter can be calculated by using $D_{e}$ from equation (3), using $K_{E}$ on th order of $10^{30}$ for the oxidation reaction

$$
\mathrm{O}_{2(\mathrm{~g})}+\frac{4}{3} \mathrm{Al}_{(\mathrm{l})} \rightarrow \frac{2}{3} \mathrm{Al}_{2} \mathrm{O}_{3(\mathrm{~s})},
$$

at $1150^{\circ} \mathrm{C}$, assuming a composition of 50 volume percent $\mathrm{Al}$, and assuming an eight hour hold at $1150^{\circ} \mathrm{C}$. The calculation yields a maximum pellet diameter of approximately 4.5 centimeters. This is smaller than the $12 \mathrm{~m}$ DMO structure which was calculated in section 22 ; however, larger pellets could be fully reacted by using longer reaction times. 


\section{2-3-2. Reaction-Bonded Mullite}

$\mathrm{Wu}$ and Lil formed reaction sintered mullite by heat treating $\mathrm{ZrSiO}_{4}$ and $\mathrm{Al}_{2} \mathrm{O}_{3}$ powder compacts. ${ }^{12} \mathrm{Wu}$ and Claussen, formed reaction-bonded mullite using $\mathrm{Al}, \mathrm{SiC}$ and $\mathrm{Al}_{2} \mathrm{O}_{3}$ as the precursor materials. ${ }^{9}$ In this systêm, the $\mathrm{Al}$ oxidizes as described above; however, the $\mathrm{SiC}$ oxidation is a solid-gas reaction which occurs as $\mathrm{CO} / \mathrm{CO}_{2}$ gas is evolved and the $\mathrm{Si}$ oxidizes to form $\mathrm{SiO}_{2}$; no liquid phase is formed during the reaction. The $108 \%$ volume increase, which accompanies the $\mathrm{SiC}$ conversior to mullite, reduced the sintering shrinkage to $0.1 \%$ in a compact of $93 \%$ theoretical density.

Si could be introduced into the system through other precursors. This research studied the oxidation behavior of RBAO compacts when an $\mathrm{Al}_{88} \mathrm{Si}_{12}$ alloy was used as the metal precursor phase. The volume change upon oxidation to mullite and alumina is calculated to be about $45 \%$ and the melting point of the alloy, $577^{\circ} \mathrm{C}$, is well below the sintering temperature of the fine oxide powder. A 50 volumf percent alloy-50 volume percent $\mathrm{Al}_{2} \mathrm{O}_{3}$ composition was chosen in an attempt to duplicate the powder processing properties of the 50 volume percent $\mathrm{Al}$ composition described in published work. ${ }^{2}$ 


\section{Experimental Procedure}

\section{3-1. Materials Selection}

The $\mathrm{Al}_{88} \mathrm{Si}_{12}$ eutectic alloy has a larger volume increase upon oxidation than pure $\mathrm{Al}$ ( $45 \%$ versus $28 \%$ ), so a $\mathrm{RBAO}$ piece made from the alloy should experience less shrinkage than one made using a pure Al precursor. From a practical standpoint, the alloy is inexpensive and available from the vendor as an easily milled powder. The as-received AlSi alloy powder consists of globular particles less than 40 microns in diameter. (Alfa-Johnson Mathey Catalog Company; Ward Hill, Massachusetts; Product Code 88322; see Fig. 3) XRD and EDS analysis of the powder detected only $\mathrm{Al}$ and $\mathrm{Si}$.

A coarse abrasive grade fused alumina powder reduced the size of the metal particles most effectively during milling. Test runs using one micron powder or globular alumina confirmed earlier findings that the fine particles succeed only in welding or deforming the metal particles. ${ }^{2,3}$ The sharp edges of the abrasive alumina are visible in the SEM micrograph of the as-received powder (about $15 \mu \mathrm{m}$ particles) shown in Figure 4. (Norton Company--Advanced Ceramics; Worcester, Massachusetts; 38 Alundum)

One batch of material contained 50 volume percent alloy, 40 volume percent $\mathrm{Al}_{2} \mathrm{O}_{3}$ and 10 volume percent $\mathrm{ZrO}_{2}$ powder added to improve the oxygen transport through the matrix. The $\mathrm{ZrO}_{2}$ was stabilized with 4.2 at.\% $\mathrm{Y}_{2} \mathrm{O}_{3}$, and the as-received powder consisted of irregular agglomerates about 25 microns along an axis as shown in Figure 5. (MEI; Flemington, NJ; SCY8) 
One weight percent (of the powder dry weight) dispersant was added to prevent agglomeration during grinding. (W.R. Grace and Company--Organic Chemical Division; Owensboro, Kentucky; Daxad 34.) The malleability of the metal phase makes the powder compact rugged enough to withstand handling without the addition of binders.

\section{3-2. Processing}

A Union Process HD-01 batch attritor (Union Process, Inc.; Akron, Ohio) was used for all of the experiments. Earlier tests using planetary ball mills and tumbling ball mills found that neither type of mill sufficiently reduced the particle size--even after 24 hours of milling. The alumina and metal powders (and zirconia powder when added) were wet ground in a $750 \mathrm{cc}$ alumina tank using $3 \mathrm{~mm}$ yttria-stabilized spherical grinding medium, a polymer-coated stirring arm and reagent grade isopropyl alcohol. The tank was charged according to the manufacturer's instructions. Each batch was milled for seven hours at $600 \mathrm{rpm}$ using a sealed lid to prevent evaporation of the isopropanol and excessive oxidation of the metal particles. Seven hours of milling was sufficient to reduce the size of all particles to one micron or less.

After milling, the grinding medium was removed with a sieve, and the slurry was left to dry in air at room temperature. The dried mixture was then lightly ground in a mortar and pestle and dried overnight in air at $100^{\circ} \mathrm{C}$ to remove any remaining solvent. The resulting powder was then pressed into approximately $6 \mathrm{~mm}$ tall cylindrical pellets in a benchtop press (Buehler Ltd.; Evanston, Illinois; Catalog No. 1315; or Carver Laboratory Press; Menomonee Falls, Wisconsin; Model C) using a $6.4 \mathrm{~mm}$ diameter stainless steel die and the minimum pressure necessary to 
permit handling of the compact (about $50 \mathrm{MPa}$ axial stress). The pellets were then vacuum sealed in balloons and cold isostatically pressed (CIP) to $400 \sim 700 \mathrm{MPa}$. This rewulted in calculated green densities of $66 \sim 73 \%$ of theoretical.

The end faces of the CIPed pellets were lightly sanded to ensure that the faces were parallel, and then the pellets were weighed and their radial and axial dimensions were measured with a micrometer. The green densities were calculated using this data. After heat treatment, the compacts were measured and weighed again for comparison with the green body measurements.

\section{3-3. Heat Treatment}

The samples were fired in a horizontal tube furnace (Applied Test Systems, Inc.; Butler, Pennsylvania; 3110 Tube Laboratory Furnace; or Orton; Westerville, Ohio; Orton Automatic Recording Dilatometer furnace). Most of the samples were heated to different temperatures between 450 and $850{ }^{\circ} \mathrm{C}$. $850^{\circ} \mathrm{C}$ was chosen as the oxidation temperature after earlier experiments showed that an extended hold at higher temperatures resulted in premature sintering of the material. The samples were heated at $5{ }^{\circ} \mathrm{C}$ per minute to the desired temperature and held for 5 420 minutes, after which, the furnace was turned off and allowed to cool to room temperature. A few samples were taken to the final sintering temperatures of $1450 \stackrel{\circ}{ } \mathrm{C}$ and $1500{ }^{\circ} \mathrm{C}$.

\section{3-4. Characterization}

The microstructure and composition of the samples were analyzed using energy dispersive spectroscopy (EDS), x-ray diffraction (XRD), 
scanning electron microscopy (SEM), and optical microscopy. Two-point electrical resistivity measurements and a few wet chemical experiments were also conducted to identify the oxidation reaction products.

\section{3-4-1. Microstructure and Reaction Rings}

SEM and reaction ring thickness samples were prepared by slicing intact pellets on a low-speed saw. Slices were taken perpendicular to the cylinder axis and as close to the center of the sample as possible. Some of the samples emerged from heat treatment heavily fractured and could be pulled apart by hand; the largest available pieces were used for microstructural analysis. The specimens were then mounted in epoxy resin and gradually polished down to one micron diamond paste. SEM samples were removed from the resin by softening the mount with a heat gun and prying out the desired sample.

Most of the samples developed well-defined concentric reaction rings. The polished samples were photographed at $6 \sim 7 \mathrm{x}$ magnification and the final pellet diameter and reaction ring thicknesses were measured from the photograph with a ruler. The diameter measurements obtained from the photograph were compared with the micrometer measurements taken directly from the fired pellets after they emerged from the furnace. If there was a disparity in the measurements, the micrometer measurement was accepted as correct, and the magnification constant for the photograph was adjusted accordingly.

\section{3-4-2. Compositional Analysis}

$\mathrm{XRD}$ analysis was carried out on polished faces when possible. Sample fragments obtained from the light-colored reaction rings and 
from the dark-colored cores were ground separately in an agate mortar and pestle. The resulting powder was then analyzed using $\mathrm{XRD}$ in order to determine if there were compositional differences between the two areas of the samples.

Most of the EDS analysis was carried out on fresh fracture faces in order to prevent contamination from the coarse alumina polishing medium. In an attempt to determine whether a glassy phase existed between the dark and light areas of the compacts, a few samples were subjected to wet chemical etching in $\mathrm{HF}$ or concentrated $\mathrm{NaOH}$ prior to SEM and EDS analysis. For the HF etch, polished samples were held at room temperature in the concentrated acid for 5 minutes, then rinsed in de-ionized water. The $\mathrm{NaOH}$ treated samples were left in a $7 \mathrm{M}$ solution at $50{ }^{\circ} \mathrm{C}$ for 10 minutes before rinsing in de-ionized water.

Two-point resistivity measurements were made across different regions of the polished samples while they were mounted in epoxy. (John Fluke Manufacturing Co., Inc.; Everett, WA; Fluke 77 Multimeter) 


\section{Results and Discussion}

\section{4-1. Reaction Rings and Microstructure}

All of the samples heated above the melting temperature of the alloy formed a cylindrical reaction layer growing inward from the pellet surface. In the sample cross sections, the reaction layer appeared as a ring concentric with the cylinder axis. The samples held at $600{ }^{\circ} \mathrm{C}$ and $700{ }^{\circ} \mathrm{C}$ for five minutes had reaction rings that were just a shade lighter than the dark gray color of the core material. However, the reaction rings of samples treated at $850^{\circ} \mathrm{C}$ were khaki colored; the core materia' remained darker than the ring despite seven hour holds at $850{ }^{\circ} \mathrm{C}$. Figure 6 is a photographic enlargement that shows the distinct reaction ring and dark core of a sample pressed at $400 \mathrm{MPa}$ and fired at $850{ }^{\circ} \mathrm{C}$ for three hours. The reaction ring is thinner in the samples CIPed at 700 MPa, suggesting that the lower porosity slowed oxygen diffusion into the center of the compact. (See Fig. 7) Figure 8 shows samples from the batch containing 10 volume percent added $\mathrm{ZrO}_{2}$ that, despite being held at $850^{\circ} \mathrm{C}$ for seven hours, preserve the dark colored core. Nonetheless, $\mathrm{ZrO}_{2}$ appears to increase oxygen transport through the compact because samples made from the batch containing 10 volume percent $\mathrm{ZrO}_{2}$ had the thickest reaction rings and the lightest colored cores for a given heat treatment. Figure 9 shows the beneficial effect of $\mathrm{ZrO}_{2}$ and low green body density on the oxidation reaction, as measured by the percent weight change in identically heat treated compacts. A table summarizing the color changes observed in the reaction rings of differently processed samples is shown in Figure 10. 
Samples heat treated below $577^{\circ} \mathrm{C}$ did not display any reaction ring, despite being held at temperature for seven hours. Samples sintered at 1450 or $1500{ }^{\circ} \mathrm{C}$ turn white throughout. Despite the fully reacted samples' uniform color, the fracture face of the original "core" material is different from the fracture face of material in the original "reaction ring". The difference in surface texture is visible with the naked eye and suggests that the two regions differ in microstructure.

All samples held at $850^{\circ} \mathrm{C}$ for three hours or longer cracked during the heat treatment. A separate series of experiments conducted with a dilatometer has shown that the cracking occurs during the extended hold at the oxidizing temperature and not while the furnace is cooling. The radial cracks run through the reaction ring and appear to either originate or terminate at the core/reaction ring interface. Tensile stresses imposed on the porous reaction layer by an expanding core, or by a shrinking reaction layer around a non-shrinking core, would account for the cracking.

SEM analysis of the samples showed that the core material is more dense than the reaction ring material. The samples held at $450{ }^{\circ} \mathrm{C}$, below $T_{M \text {,alloy }}=577^{\circ} \mathrm{C}$, for seven hours showed no difference microstructurally between the center and the edge of the specimen. (See Fig. 11) However, the micrographs in Figure 12 show the difference in porosity between the core and the reaction ring of samples held at $600{ }^{\circ} \mathrm{C}$ for just five minutes. Figure 13 shows micrographs taken of the core and the reaction ring of a sample heated at $850{ }^{\circ} \mathrm{C}$ for three hours. The grain size remains on the order of a micron or less, demonstrating that excessive grain growth does not occur, and the pores are generally several particle diameters across. An interface microstructure between 
the reaction ring and the core could not be detected. Attempts to preferentially etch the interface with $\mathrm{HF}$ and $\mathrm{NaOH}$ failed.

All of the samples exhibited a weight increase during heat treatment, including the sample held at $450{ }^{\circ} \mathrm{C}$ which showed no other evidence of reaction. Figure 14 shows graphs of the heat treatment schedule and the corresponding weight gain and ring thickness for samples CIPed at $400 \mathrm{MPa}, 0$ volume percent added $\mathrm{ZrO}_{2}$. The sample weight increases rapidily as the reaction ring is established, then remains essentially unchanged for the rest of the experiment.

The $19 \%$ weight gain of fully reacted material is only $60 \%$ of the calculated weight change for the composition. This percentage agrees with Claussen's findings that as much as $40 \%$ of the metal phase reacts prior to heat treatment. The pre-heat treatment passivation layer makes the metal powder safe to handle during the milling and compaction steps of the process. However, the pre-oxidized material cannot contribute to pore-filling and shrinkage reduction during the reaction bonding process. In addition, the calculated porosity of the green body is based on theoretical density calculations for the original alloy/alumina composition. The weight change data suggest that the green compact contained less volume percent alloy than expected; thus, the initial porosity could be higher than expected. Higher initial porosity should improve the oxidation rate at first; however, it would cause increased shrinkage during the the sintering stage of the heat treatment. If hydroxides such as $\mathrm{AlO}(\mathrm{OH})$ or $\mathrm{Al}(\mathrm{OH})_{\mathrm{x}}$ have formed, then the dehydration of the hydroxides could also increase volume shrinkage during heat treatment. XRD did not detect aluminum hydroxides, but the hydroxide may have been amorphous. Improved laboratory 
practices, such as baking out all grinding tank parts, using anhydrous isopropanol and drying the slurry under vacuum, would reduce the amount of pre-heat treatment oxide.

Figure 15 shows how the initial reaction ring growth is accompanied by a $0.5 \%$ linear shrinkage in the samples. However, the sample is steadily increasing in mass during this period. The weight gain suggests that the metal is being oxidized, but the $1 \sim 2 \%$ linear expansion predicted by Claussen, et al., is being counteracted by a shrinkage mechanism. One suck mechanism would be the aluminum hydroxide dehydration mentioned above. The shrinkage could also be explained by particle rearrangement due to molten metal flowing between the oxide particles. As discussed in section 2-3-1, Claussen, et al., proposed that milling produced an oxide skin on the metal particles which prevented the molten metal from flowing between the particles during the initial heating stage. Thus, the connected porosity of the compact was preserved until late in the heating schedule. If the oxide skin were not stable, the metal could flow between the oxide grains immediately upon melting, which would lead to particle rearrangement and seal-off the high diffusion rate paths to the center of the compact. The presence of $\mathrm{Si}$ as an alloying element in both the DMO process and this research raises the possibility of similar oxidation mechanisms operating in both systems. The role of $\mathrm{Si}$ in the DMO alloy mixture is unclear. Newkirk and Sindel find that $\mathrm{Si}$ and $\mathrm{Mg}$ must both be present to destabilize the aluminum passivation layer; 7,22 Thiele, however, finds that $\mathrm{Si}$ alone is sufficient to inhibit formation of a proctective oxide film. ${ }^{23}$ The high purity $\mathrm{Al}_{2} \mathrm{O}_{3}$ abrasive used in this experiment is an unlikely source of $\mathrm{MgO}$; however, $\mathrm{Mg}$ may have entered the system from the $\mathrm{Al}_{2} \mathrm{O}_{3}$ grinding 
tank or as a trace element in the $\mathrm{Al}_{88} \mathrm{Si}_{12}$ alloy. As mentioned in section 2-2, MgO-spinel double layers caused darkening of the metal surface; therefore, small amounts of Mg would also explain the dark color of the core material. Neither EDS nor XRD detected Mg in the milled powders but very small amounts would be sufficient to affect the color; Aritolin, et al., found that as little as $0.7 \mathrm{wt} . \% \mathrm{Mg}$ was sufficient to darken the $\alpha$ $\mathrm{Al}_{2} \mathrm{O}_{3}$ in their composite. ${ }^{14}$

An unstable oxide layer would help to explain the nearly fixed reaction ring thickness and dense core material. The reaction ring thickness would represent the extent to which oxygen diffusion rates were fast eriough to replenish the gas in the pores as the sample was heated at $5^{\circ} \mathrm{C} / \mathrm{min}$. through $577^{\circ} \mathrm{C}$. The model assumes that the oxygen in the pores is rapidly consumed during the early stages of heat treatment, and the oxygen diffusing in through the pores is denleted by the material closest to the sample surface. The pores are on the order of one micron or larger in diameter, so that Knudsen diffusion can be ignored. As the compact is heated above the alloy melting temperature, most of the material near the surface of the sample has already been oxidized via gas-solid reactions. However, in the center of the compact a higher percentage of the material remains unreacted and an unstable passivation layer over the alloy particles allows the molten metal to flow between the oxide grains and into the pores. Once the high diffusion rate paths are closed, oxidation occurs through much slower ionic transport mechanisms such as oxygen diffusion along grain boundaries or cation diffusion through the reaction layer. Unlike the simplified system described by Eq.(2) in section 2-3-1, the reaction is now both chemical reaction and diffusion rate controlled and must be divided into 
two parts to account for complete oxidation of the reaction ring followed by conversion of the inner core. Szekely, Evans and Sohn present solutions for a porous slab composed of flat grains, $F_{p}=F_{g}=1$, where $F_{g}$ is the shape factor for the grains. For spherical grains in a cylindrical pellet one must resort to a numerical solution which is beyond the scope of this work. ${ }^{21}$

\section{4-2. Composition}

The original batch compositions contained 93 at.\% $\mathrm{Al}$ and 7 at.\% $\mathrm{Si}$ in the batch without added $\mathrm{ZrO}_{2}$, and 88 at.\% $\mathrm{Al}, 7$ at.\% $\mathrm{Si}$ and 5 at.\% $\mathrm{Zr}$ in the batch with $\mathrm{ZrO}_{2}$. EDS analysis showed that the unfired material from the batch without added $\mathrm{ZrO}_{2}$ contained approximately 90 at.\% $\mathrm{Al}, 6$ at.\% $\mathrm{Si}$, and 4 at.\% $\mathrm{Zr}$. The $\mathrm{Zr}$ fraction is attributed to wear of the $\mathrm{ZrO}_{2}$ grinding media used to comminute the powder. If these proportions remain unchanged during the heat treatment, the fully reacted material would contain $12 \mathrm{~mol} \% \mathrm{SiO}_{2}$ and $80 \mathrm{~mol} . \% \mathrm{Al}_{2} \mathrm{O}_{3}$.

In general, the $\mathrm{Si}$ concentration in the reaction ring decreased slightly with time at temperature, while the core material consistently contained approximately 9 at.\% $\mathrm{Si}$. The $\mathrm{ZrO}_{2}$ concentration remained constant throughout. The EDS data are summarized in Table 1. One could speculate that an oxide reaction layer formed around the semimolten core material. Wagner has calculated that during the oxidation of alloys, the oxide with the faster growth rate will tend to grow over the slow forming oxide. The reaction layer would then further retard oxidation of the slowly reacting metal. ${ }^{24}$ The lower melting temperature Al would be expected to have a faster cation diffusion rate through the 
Table 1. Variation in Composition Across Cross-Sections

\begin{tabular}{|c|c|c|c|}
\hline Sample & At.\% Al & At.\% Si & At. $\% \mathrm{Zr}$ \\
\hline Unfired & 90 & 6 & 4 \\
\hline $850^{\circ} \mathrm{C}$, ring & 88 & 6 & 5 \\
\hline 5 min., core & 86 & 9 & 5 \\
\hline $850^{\circ} \mathrm{C}$, ring & 90 & 5 & 5 \\
\hline $3 \mathrm{hrs}$., core & 87 & 9 & 4 \\
\hline $1500^{\circ} \mathrm{C}$, ring & 91 & 4 & 5 \\
\hline $1 \mathrm{hr}$., core & 87 & 9 & 4 \\
\hline
\end{tabular}

reaction layer than the $\mathrm{Si}$. Thus, as the reaction progressed, the $\mathrm{Al}_{2} \mathrm{O}_{3}$ concentration in the reaction ring would increase and the $\mathrm{Al}$ concentration in the core would decrease. In order to raise the $\mathrm{Si}$ concentration to 9 at.\% in one mole of powder, $62 \%$ of the $\mathrm{Al}$ from the $\mathrm{Al}$ alloy would have to be removed. The extra $\mathrm{Al}$ added to one mole of powder would drop the Si concentration to about 5 at.\%. It seems unlikely that diffusion alone could transfer $62 \%$ of the Al metal out of the core. If Mig is present, DMO mass transfer processes may also be operating, although no evidence of such was lound by SEM. Such large scale mass transfer occurring at the core/reaction ring interface would generate considerable stresses. As material is added to the interface, the inner circumference of the reaction ring would experir ace radial compressive stresses which would be transferred to the interface as a circumferential tensile stress. The radial cracking observed in samples heat treated for longer times can be attributed to a combination of this 
mass transfer stress and the stresses induced by sintering shrinkage of the porous reaction layer.

SEM and EDS techniques were unsuccessful in identifying an interface microstructure or composition. If, for example, a silicate phase had preferentially migrated to the interface, the HF etch would have resulted in etch pits at the interface. Other researchers have identified $\mathrm{Si}$ and $\mathrm{SiO}_{2}$ at $\mathrm{Al}$ alloy- $\mathrm{Al}_{2} \mathrm{O}_{3}$ composite interfaces. ${ }^{14,25} \mathrm{Si}$ or $\mathrm{Mg}$ at the interface would also be indicative of a DMO type double layer formation. The concentrated $\mathrm{NaOH}$ etched the core material more than the reaction ring material of a sample heated to $850^{\circ} \mathrm{C}$ and held for 5 minutes, which indicates a larger amount of unreacted material in the core. (See Fig. 16)

Corundum and yttria stabilized $\mathrm{ZrO}_{2}$ were the freq:1ently observed compounds using XRD. Despite the EDS results, no Si containing compound could be positively identified in the core of a sample held at $850^{\circ} \mathrm{C}$ for 7 hours. Si solubility in $\mathrm{Al}$ is limited to 1.5 at.\%, so the remaining 7.5 at.\% $\mathrm{Si}$ in the core could be in an amorphous phase or in the phase represented by the unidentified peaks in the XRD scan shown in Figure 17. Si reappeared in the form of $\mathrm{ZrSiO}_{4}$ found in a sample heated to $1400^{\circ} \mathrm{C}$; however, a sample from the same batch heated to $1500{ }^{\circ} \mathrm{C}$, above the decomposition temperature of $\mathrm{ZrSiO}_{4}$, showed only corundum and $\mathrm{ZrO}_{2}$. The heat treatment temperatures were too low for mullite formation, but if the $\mathrm{ZrSiO}_{4}$ decomposition resulted in amorphous $\mathrm{SiO}_{2}$ instead of cristobalite, XRD would be unable to detect the $4 \sim 5$ at. $\%$ Si previously detected by EDS. 


\section{4-3. Resistivity Measurements}

The green compacts, samples heated to $450^{\circ} \mathrm{C}$, and samples heated at $850^{\circ} \mathrm{C}$ for loriger than five minutes are insulating. However the resistivity of the core and the reaction ring in the remaining samples varies as shown in Figure 18. The reaction rings of the samples CIPed at $400 \mathrm{MP}_{3}$ and heated at $850^{\circ} \mathrm{C}$ for five minutes are also insulating. The results suggest that the milling process forms a passivation layer on the metal particles, and the extended heat treatment oxidizes the remaining metal. However, as proposed in the previous section, heating the compact above the alloy melting temperature destabilizes the oxide or coats it with a lower resistivity material. 


\section{Conclusion}

The success of the RBAO process depends upon the aluminum passivation layer to preserve the porous microstructure until late in the heat treatment process. Therefore, the technique has been successful with pure alumina systems and in mullite formation in which the $\mathrm{SiO}_{2}$ is formed from a solid that does not alter the surface chemistry of the aluminum metal. The results of this research suggest that the $\mathrm{Al}_{88} \mathrm{Si}_{12}$ alloy does not form a stable oxide layer and, as a result, forms cracked partially reacted bodies.

The reaction rings, non-uniform composition and non-uniform microstructure in the compacts are attributed to the alloy flowing between the oxide grains and closing continuous porosity early in the heat treatment process. The resistivity data suggest that a passivation layer is formed during the milling process but this layer cannot contain the alloy once it has melted, nor is the oxide shell rigid enough to hold the ceramic grains apart and prevent particle rearrangement. The darkening of the core material and the presence of $\mathrm{Si}$ in the composition suggest the possibility of DMO-type oxidation mechanisms; however, characterization techniques to date have not detected $\mathrm{Mg}$. The $\mathrm{Mg}$ is crnsidered critical to the formation of a dark surface MgO-spinel double layer (or $\mathrm{Mg}$ doped $\alpha-\mathrm{Al}_{2} \mathrm{O}_{3}$ layer) and to suppressed passivation of the metal. Further study is required to identify the chemical species at the reaction interface. 


\section{References}

1) G. MacZura, K.J. Moody and E.M. Anderson, Ceramic Bulletin, 71 (5) (1992) 780.

2) N. Claussen, N.A. Travitzky and S. Wu, Ceram. Eng. Sci. Proc., 11 (78) (1990) 806.

3) N. Claussen, T. Le and S. Wu, J. Europ. Cer. Soc., 5 (1989) 29.

4) W.D. Kingery, H.K. Bowen and D.R. Uhlmann, Introduction to Ceramics, 2nd ed., (New York: John Wiley \& Sons, 1976) 508.

5) M.E. Washburn and W.S. Coblenz, Cer. Bull., 67 (2) (1988) 356.

6) A.J. Moulson, J. Mat. Sci., 14 (1979) 1017.

7) M. Newkirk, et al., J. Mater. Res., 1 (1) (1986) 81.

8) O. Salas, et al., J. Mat. Res., 6 (9) (1991) 1964.

9) S. Wu and N. Claussen, J. Am. Ceram. Soc., 74 (10) (1991) 2460.

10) B.R. Marple and D.J. Green, J. Am. Ceram. Soc., 71 (11) (1988) C471 .

11) M.D. Sacks, N. Bozkurt and G.W. Scheiffele, J. Am. Ceram. Soc., 74 (10) (1991) 2428.

12) J.M. Wu and C.M. Lin, J. Mat. Sci., 26 (1991) 4631.

13) M.K. Aghajanian, et al., J. Mat. Sci., 24 (1989) 658.

14) S. Antolin, A.S. Nagelberg and D.K. Creber, J. Am. Ceram. Soc., 75 (2) (1992) 447.

15) J.D. Hodge in Ceramic Transactions: Sintering of Advanced Ceramics, C.A. Handwerker, J.E. Blendell and W.A. Kaysser, eds., (Westerville, OH: Am. Ceram. Soc., 1990) p. 416.

16) J.W. Cahn and R.B. Heady, J. Am. Ceram. Soc., 53 (7) (1970) 406. 
17) N. Claussen and S. Wu, presented at the 4th Inter. Conf. Cer.

Powder Proc. Sci., Nagoya, Japan (March 1991).

18) W.D. Kingery, et al., J. Am. Ceram. Soc., 42 (8) (1959) 393.

19) J. Requena, R. Moreno and J.S. Moya in Novel Ceramic Fabrication Processes and Applications, R.W. Davidge, ed., (Shelton, U.K.: The Institute of Ceramics, 1986) p. 104.

20) J.D. French, et al., J. Am. Ceram. Soc., 75 (2) (1992) 418.

21) J. Szekely, J.W. Evans, and H.Y. Sohn, Gas-Solid Reactions (New York: Academic Press, 1976) pp. 130-138.

22) M. Sindel, N.A. Travitzky, and N. Claussen, J. Am. Ceram. Soc., 73 (9) (1990) 2615.

23) W. Thiele, Aluminum, 38 (1962) 770.

24) C. Wagner, J. Electrochem. Soc., 103 (11) (1956) 627.

25) R. Molins, J.D. Bartout and Y. Bienvenu, Mat. Sci. and Eng., A135 (1991) 111. 


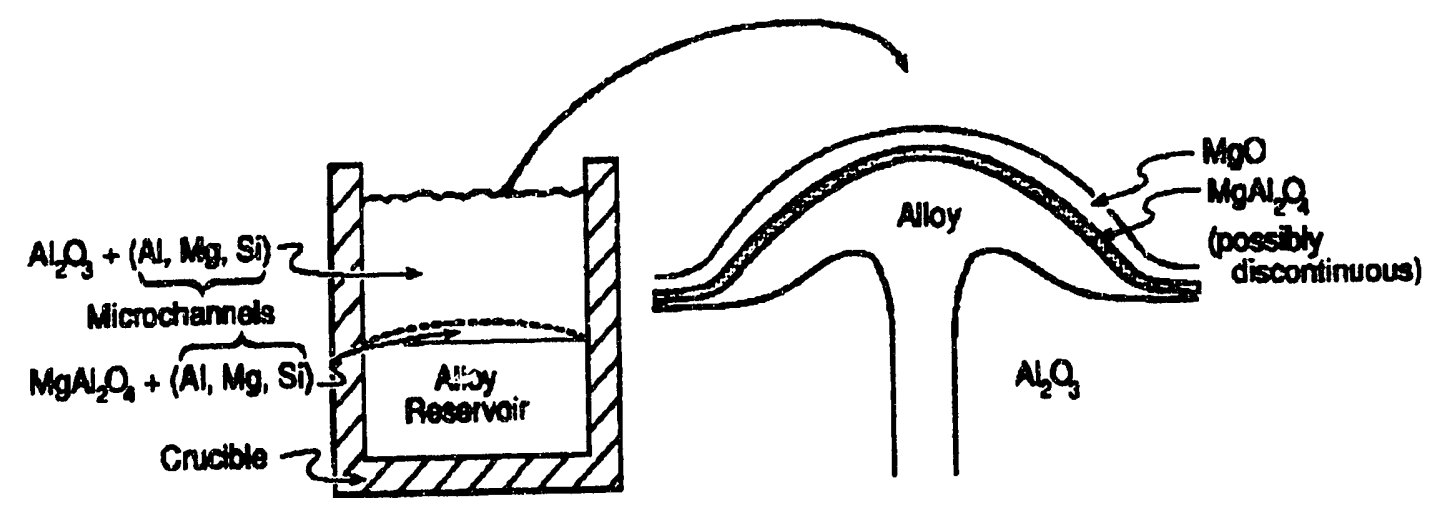

Figure 1. MgO-Spinel double layer formation during early stage oxidation in DMO process as described by Salas. ${ }^{8}$ 


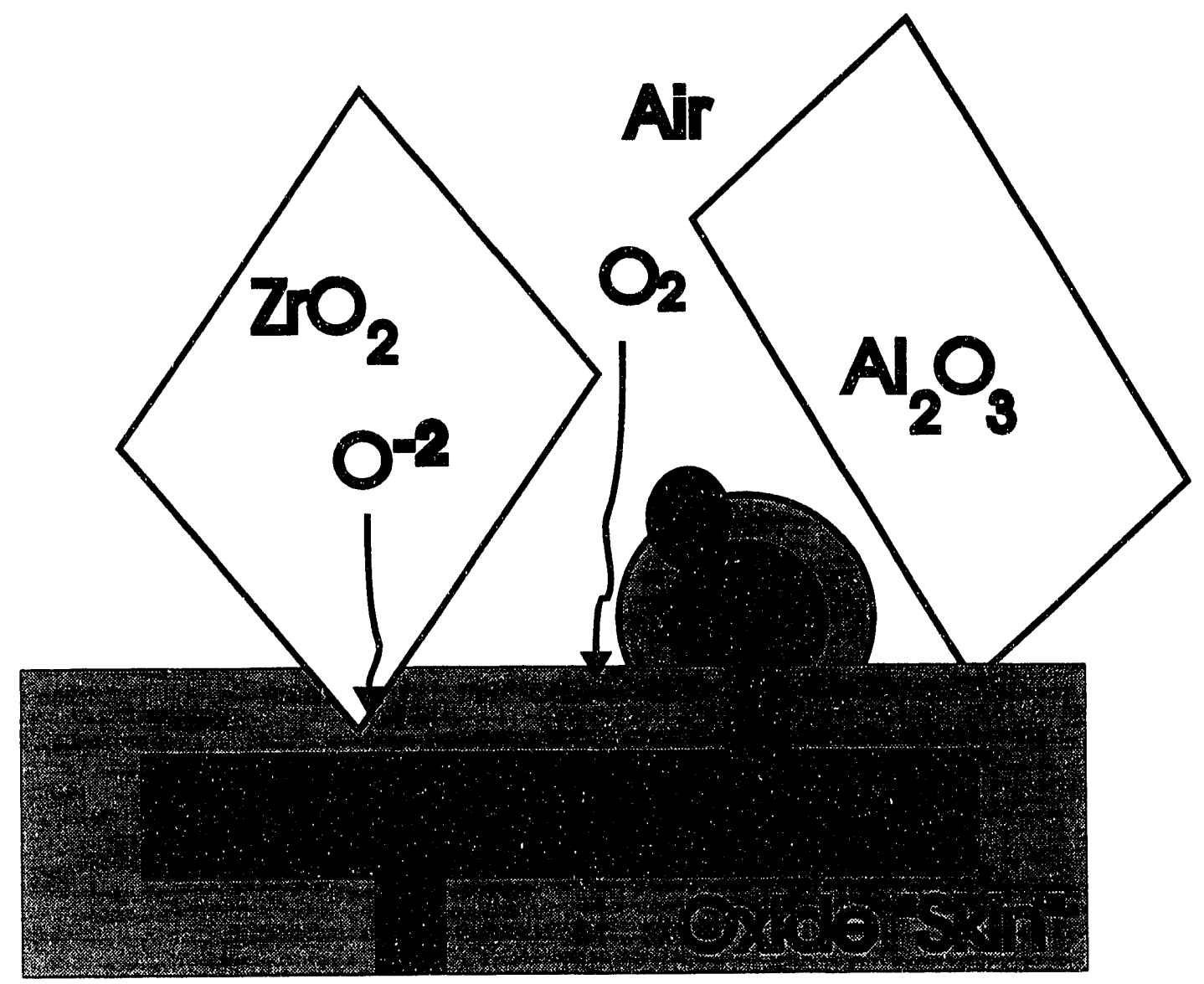

Figure 2. Oxidation model in reaction-bonded alumina as proposed by Claussen, et al. ${ }^{2}$ 


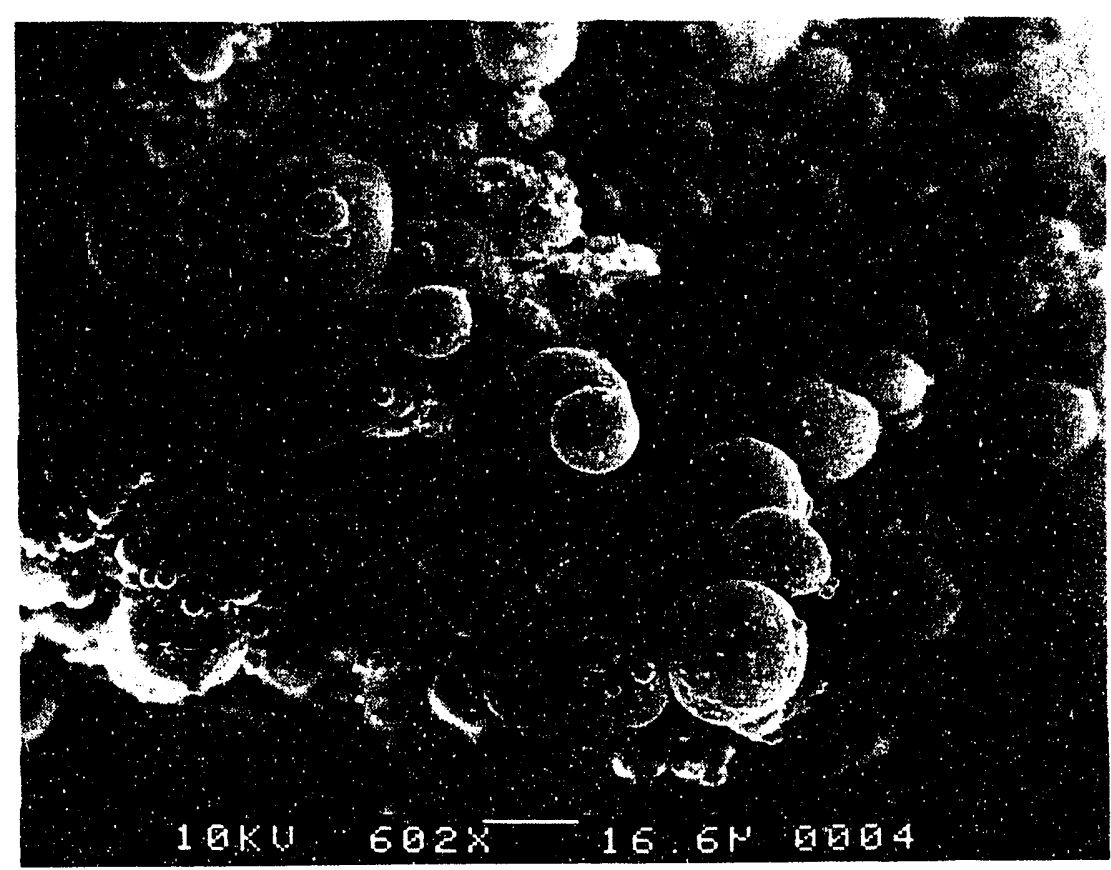

XBB 920-10030

Figure 3. SEM micrograph of as-received $\mathrm{Al}_{88} \mathrm{Si}_{12}$ powder. 


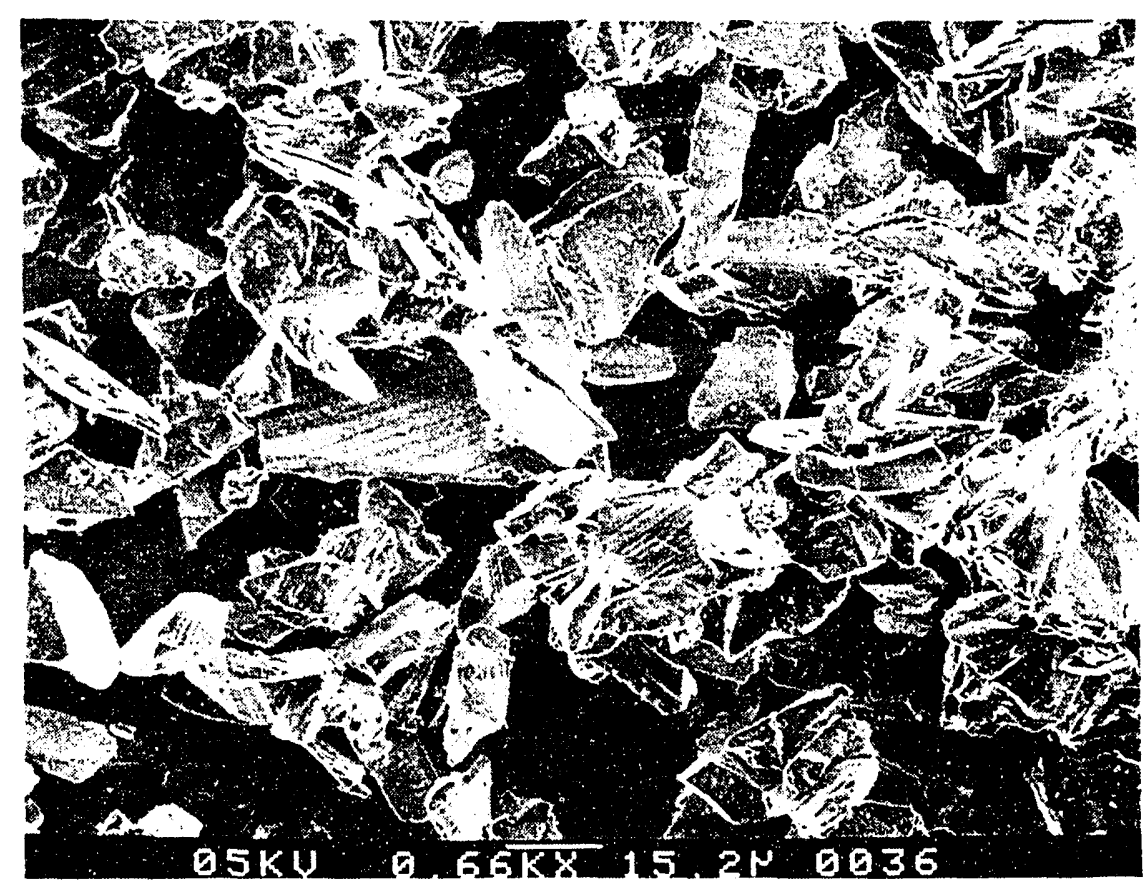

Figure 4. SEM micrograph of as-received $\mathrm{Al}_{2} \mathrm{O}_{3}$ abrasive.

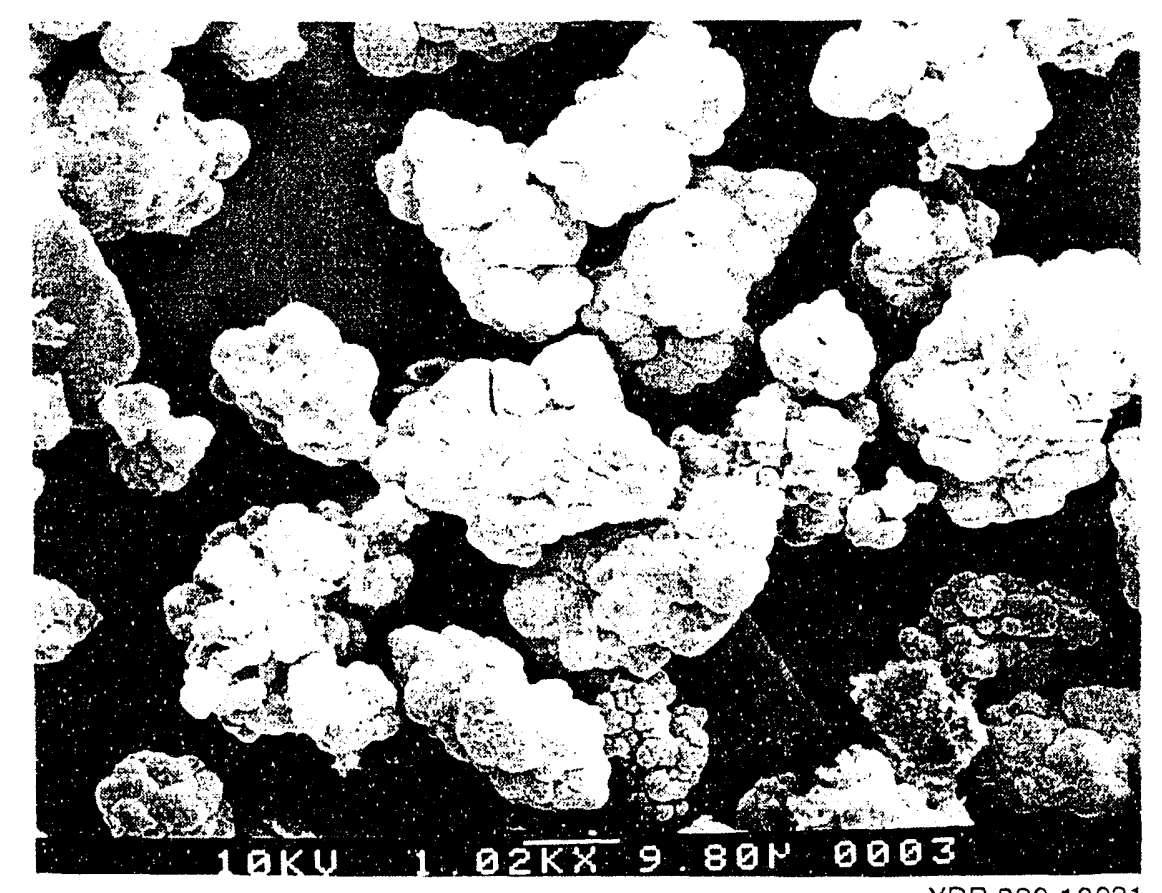

XBB 920-10031

Figure 5. SEM micrograph of as-received $\mathrm{ZrO}_{2}$ powder. 

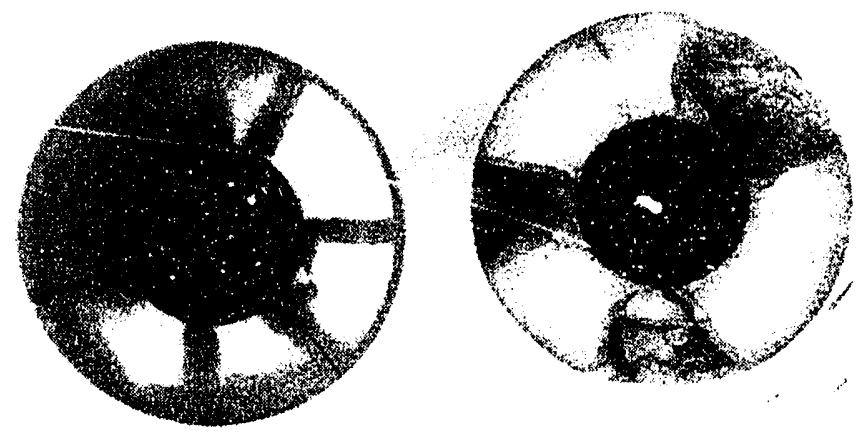

$2 \mathrm{~mm}$

Figure 6. Photo-enlargement of polished samples; CIP $400 \mathrm{MPa}, 850^{\circ} \mathrm{C}$ for 3 hours. Discoloration along crack edges due to epoxy penetration during vacuum infiltration mounting.
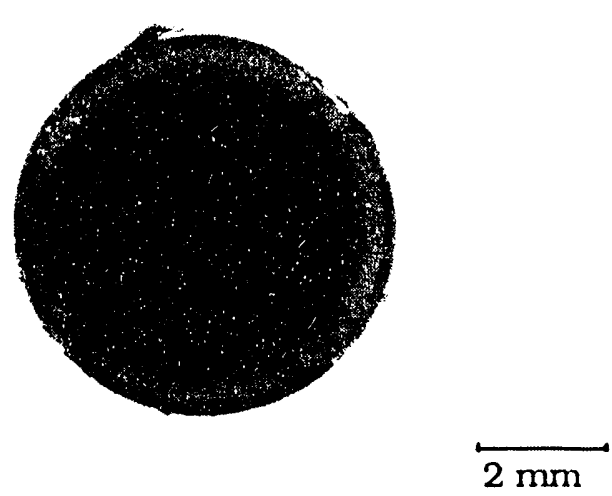

XBB 920-10032

Figure 7. Photo-enlargement of polished sample; CIP $700 \mathrm{MPa}, 850^{\circ} \mathrm{C}$ for 5 minutes. Note slightly darker core material just inside core/reaction ring interface. 

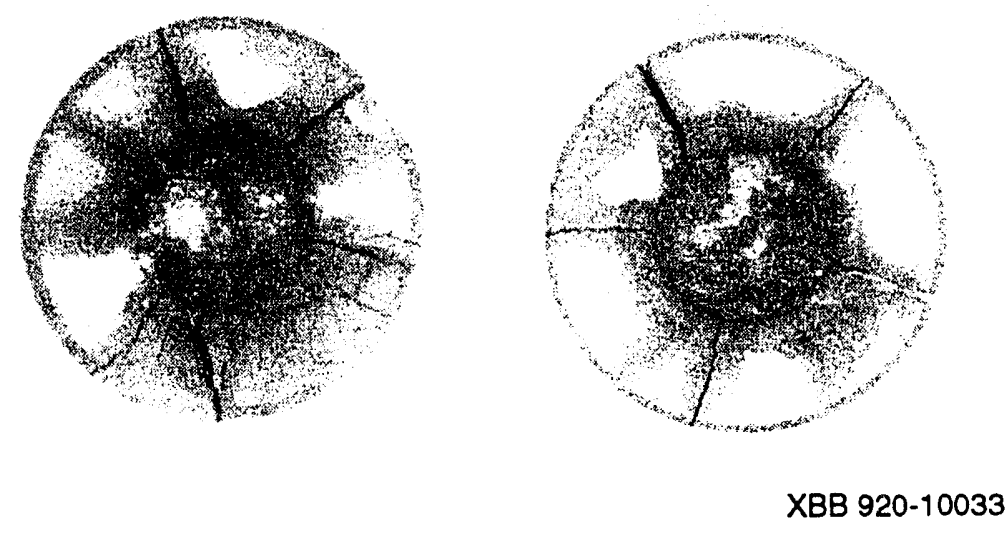

$2 \mathrm{~mm}$

Figure 8. Photo-enlargement of polished samples; CIP $400 \mathrm{MPa}, 10$ vol.\% $\mathrm{ZrO}_{2}, 850^{\circ} \mathrm{C}$ for 7 hours. Discoloration along crack edges due to epoxy penetration during vacuum infiltration mounting. 
Percent Weight Change vs. CIP Pressure

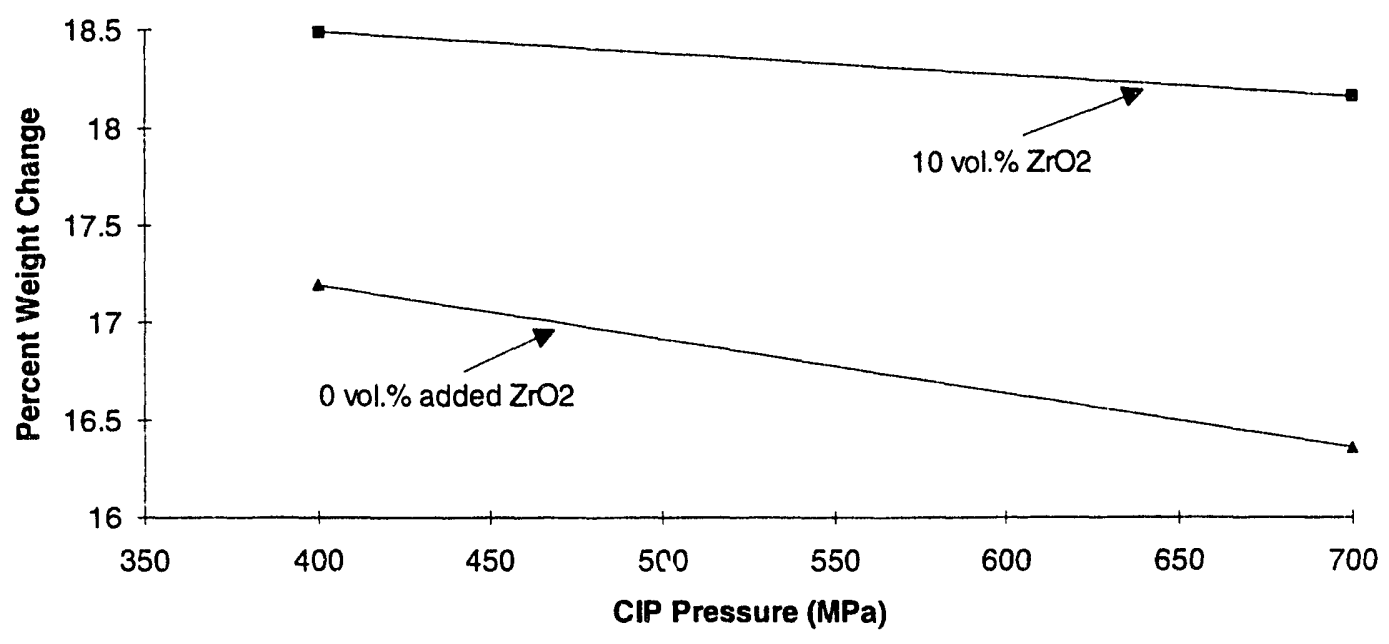

Figure 9. Chart showing how higher green density (higher compacting pressures) and lower $\mathrm{ZrO}_{2}$ content reduce the extent of the reaction as measured by percent weight change in the samples. Samples were fired at $850{ }^{\circ} \mathrm{C}$ for 7 hours. 


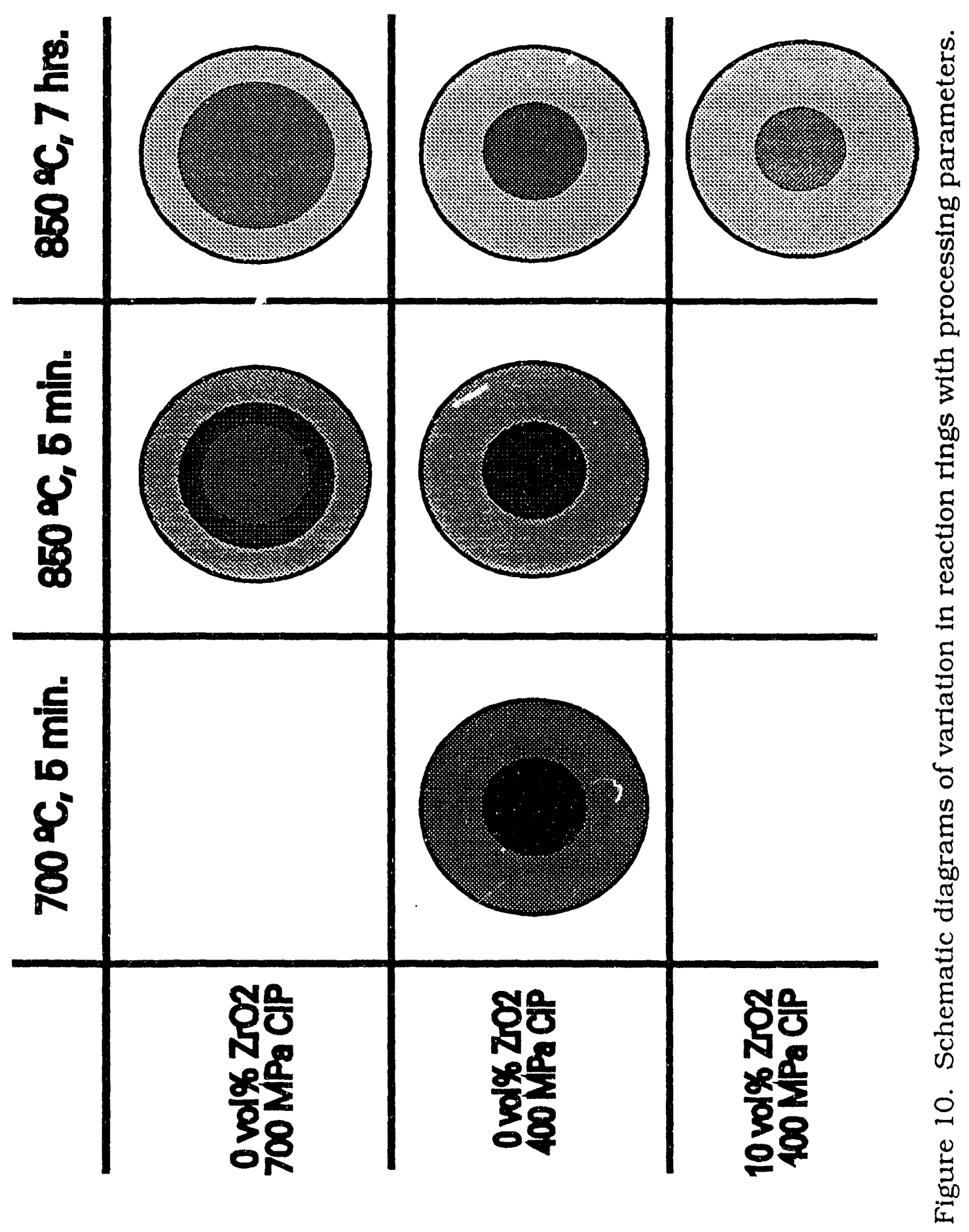




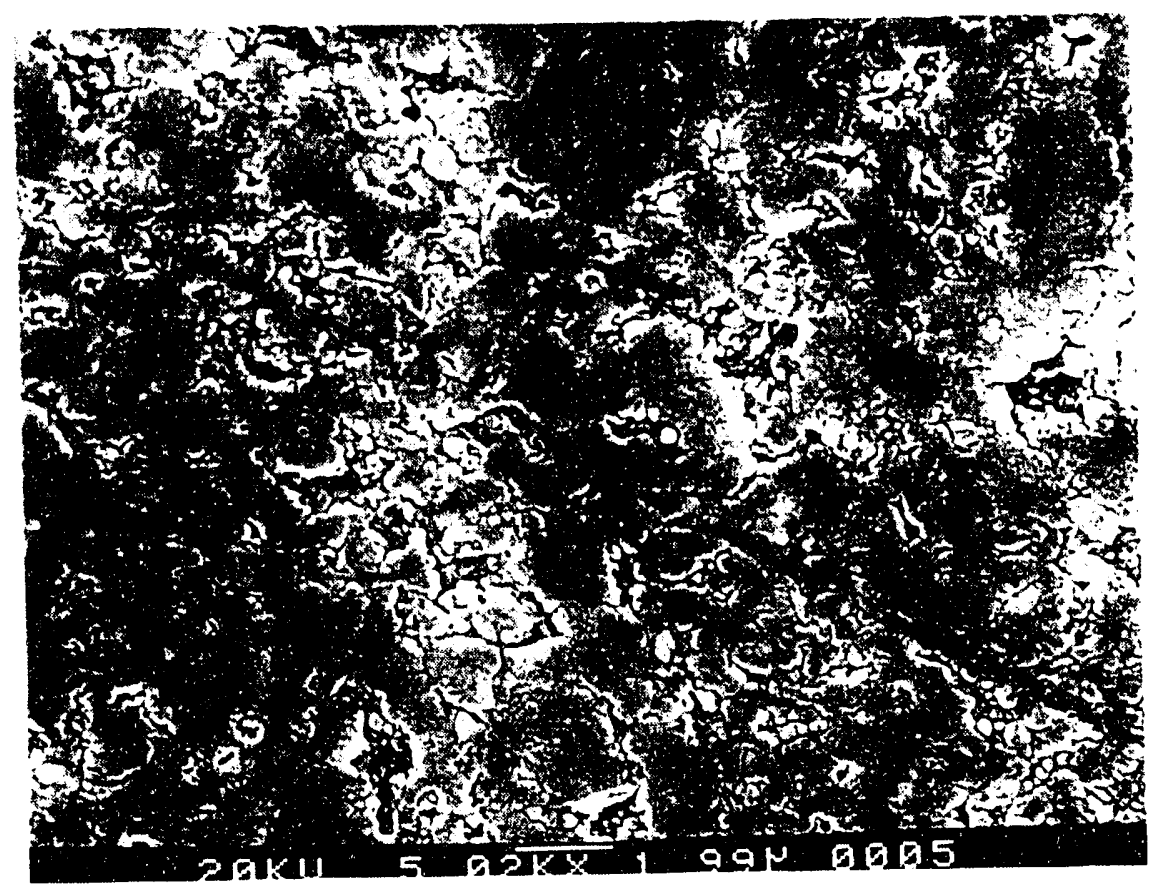

Figure 1 la. SEM micrograph of core material of polished sample: CIP $400 \mathrm{MPa} .450^{\circ} \mathrm{C}$ for 7 hours.

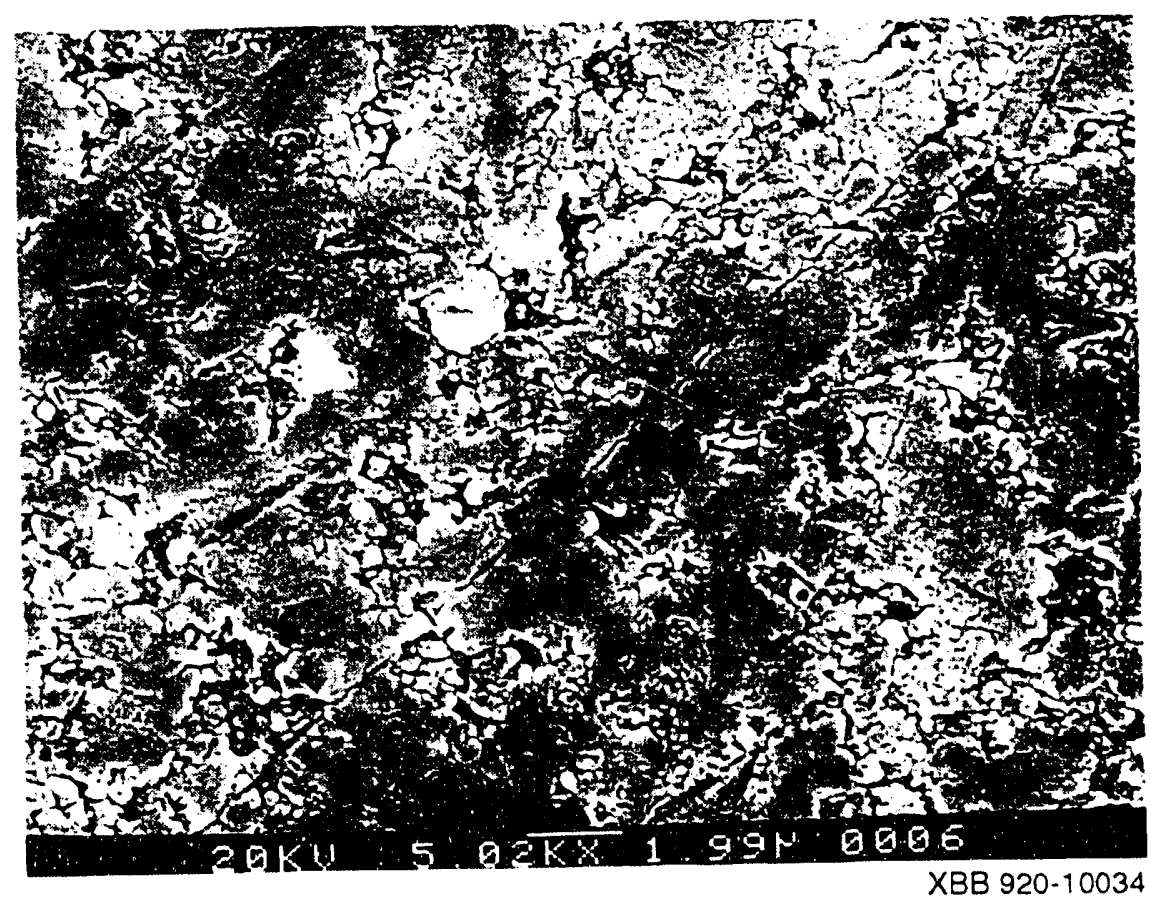

Figure 1 lb. SEM micrograph of material from near the edge of the same sample. 


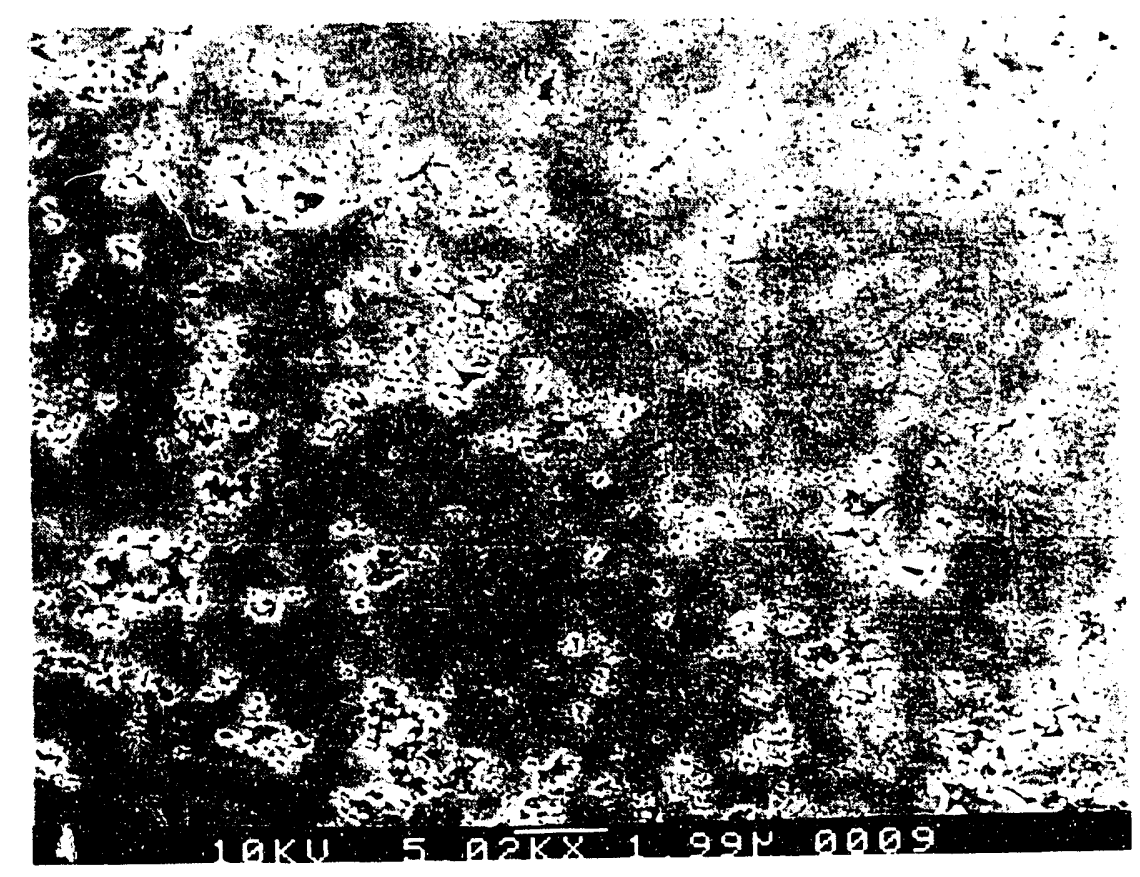

Figure 12a. SEM micrograph of core material of polished sample: CIP $400 \mathrm{MPa} .600$ "C for 5 minutes.

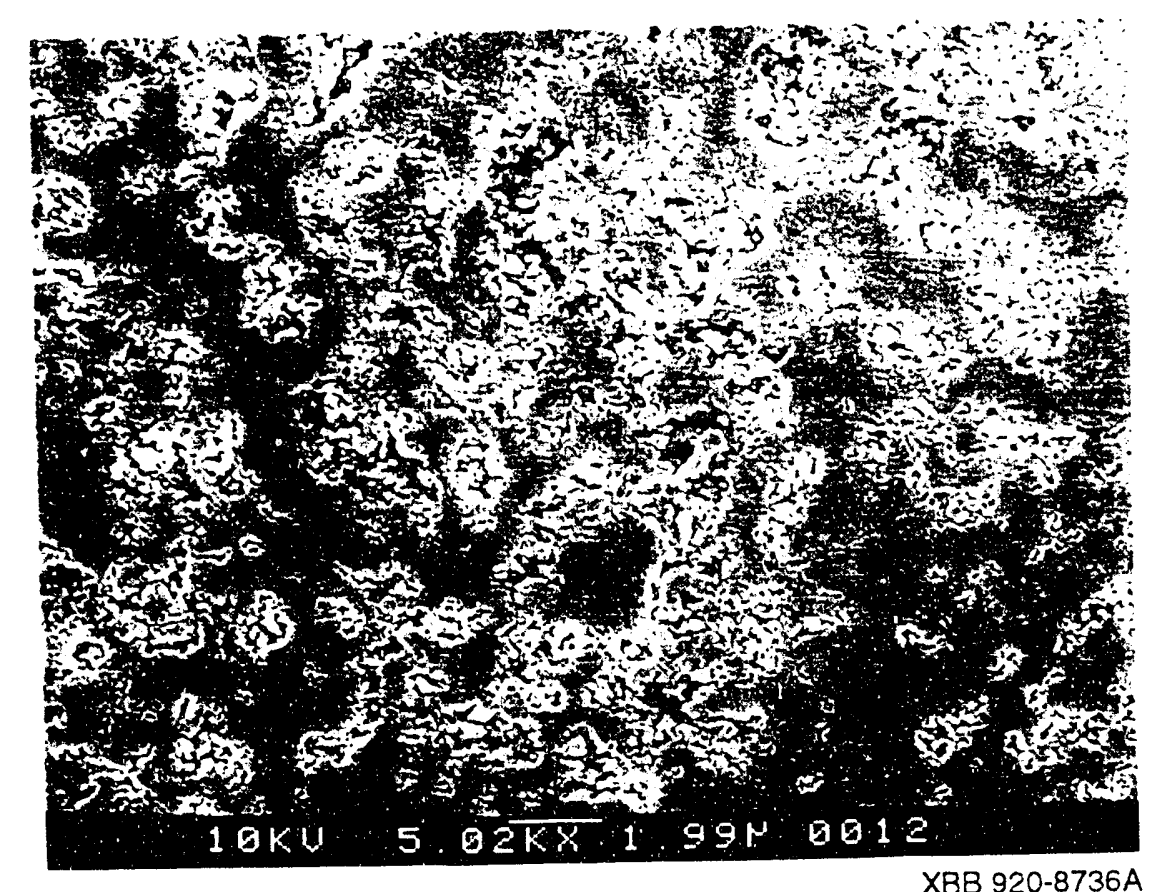

Figure $12 \mathrm{~b}$. SEM micrograph of reaction ring material from the same sample. 


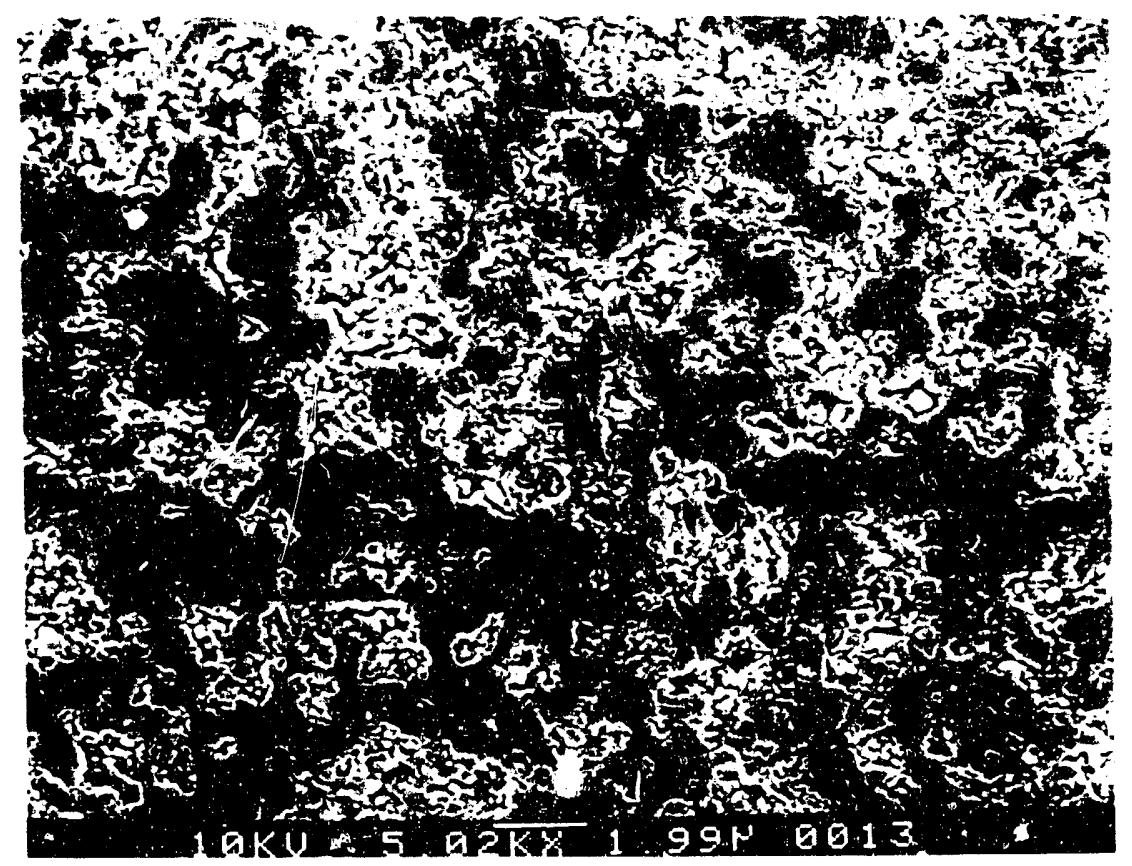

Figure 13a. SEM micrograph of the core material of polished sample: CIP $400 \mathrm{MPa} .850$ "C for 3 hours.

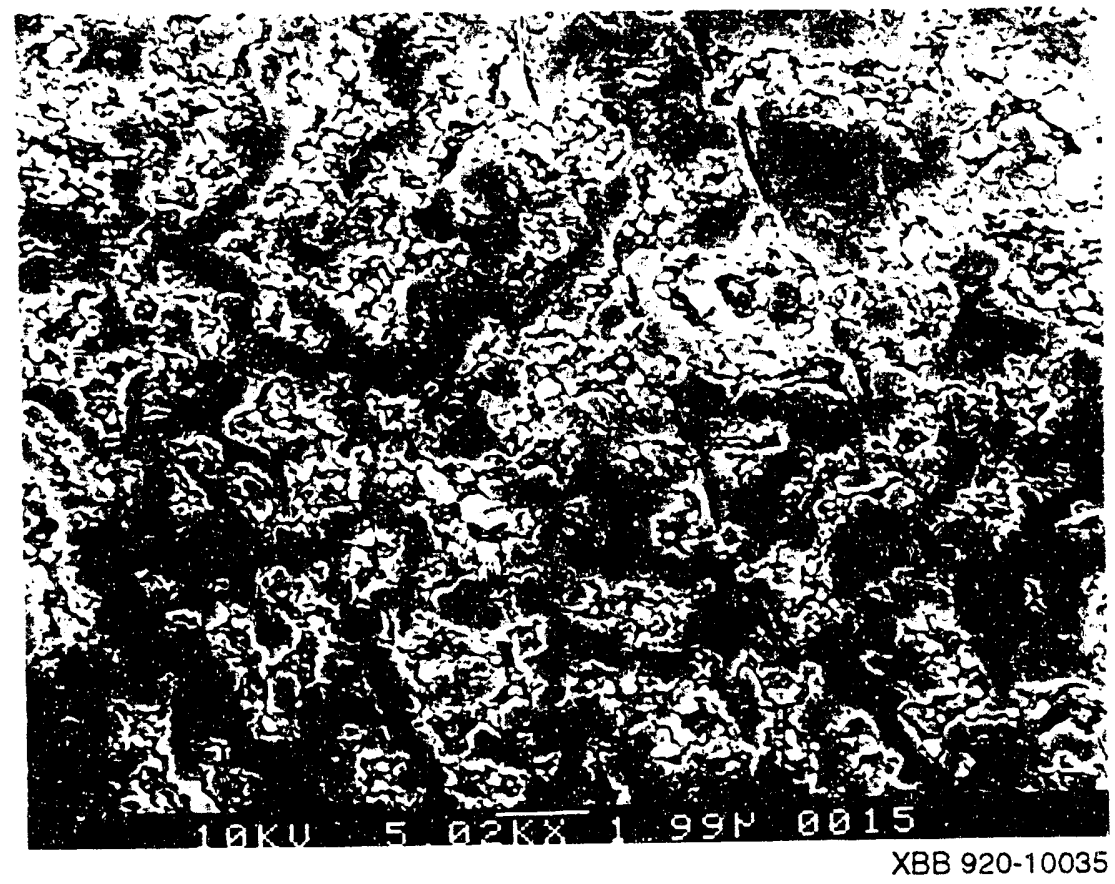

Figure 13b. SEM micrograph of reaction ring material from the same samplc. 


\section{Reaction Parameters vs. Heat Treatment}
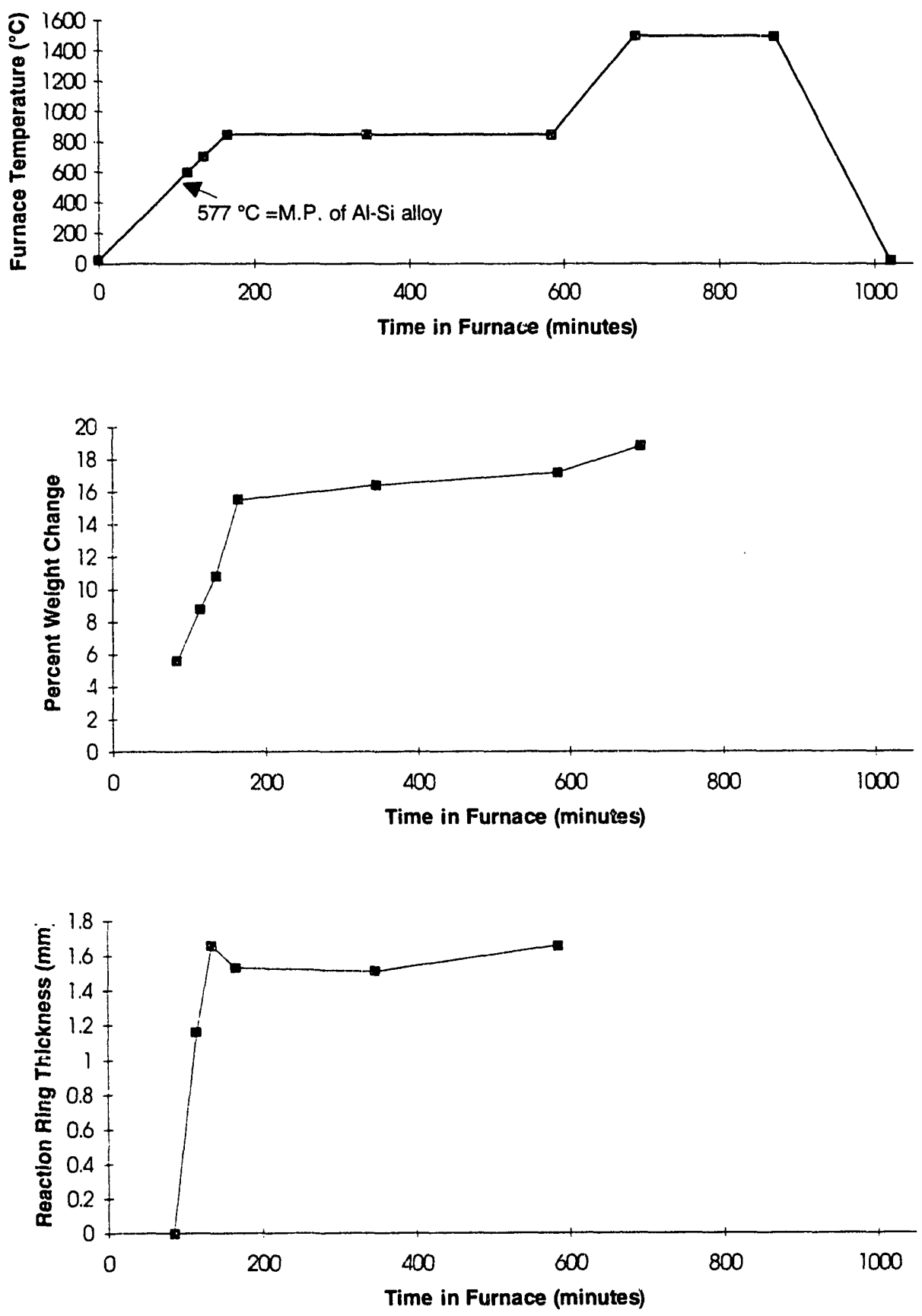

Figure 14. Charts showing variation in percent weight change and reaction ring thickness with heating temperature. All samples pressed at $400 \mathrm{MPa}$, no added $\mathrm{ZrO}_{2}$. 
Weight and Dimensional Changes vs. Firing Temperature
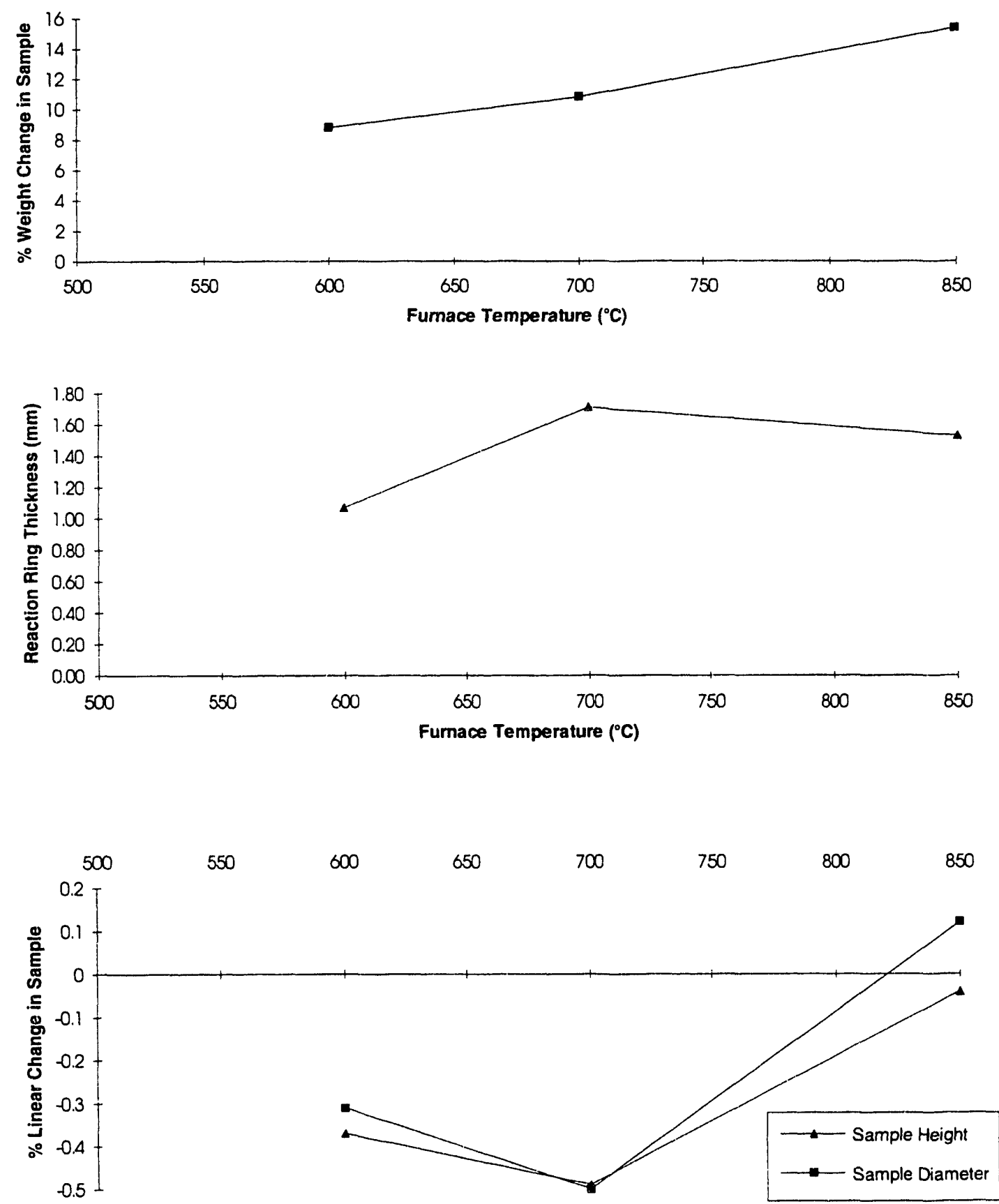

Figure 15. Charts showing dimensional changes in samples as the heating schedule progresses. Compare with Figure 14. 


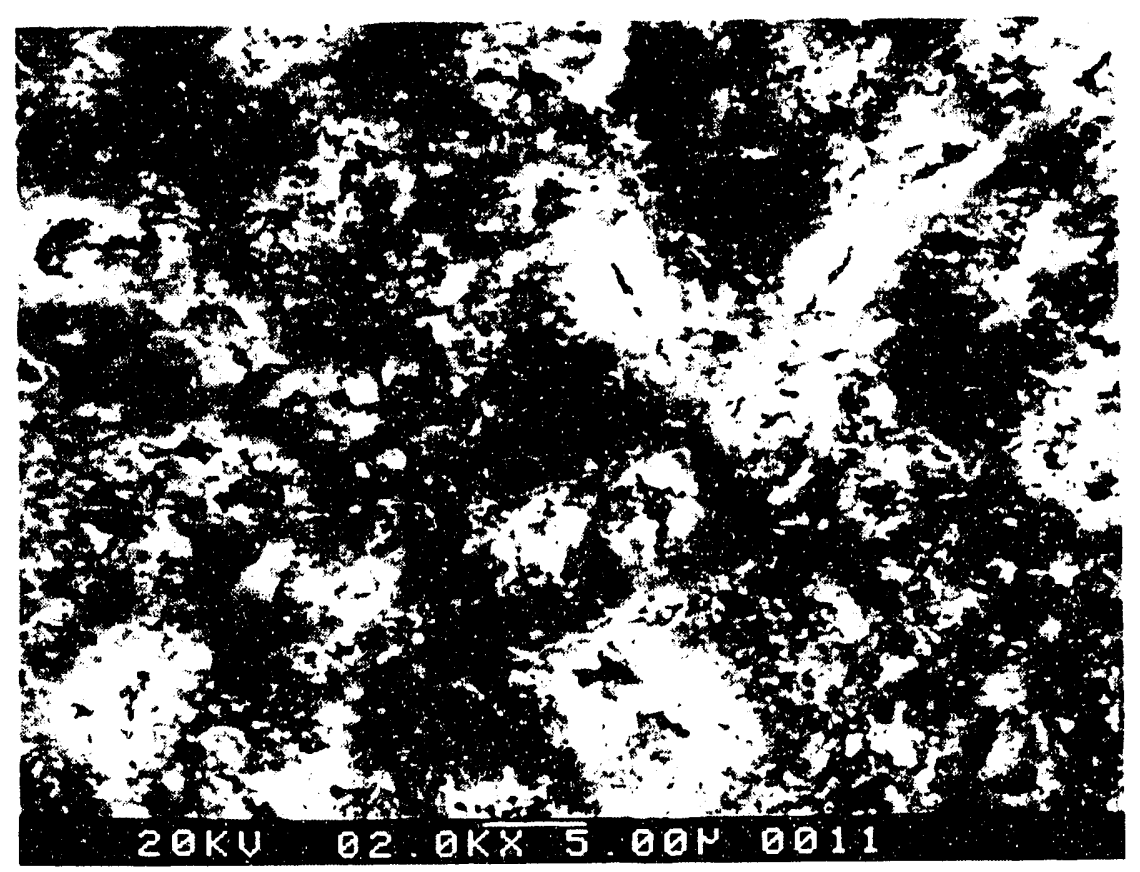

Figure 16a. SEM micrograph of the core material of a sample polished then etched with $\mathrm{NaOH}$ : CIP $700 \mathrm{MPa}, 850^{\circ} \mathrm{C}$ for 5 minutes.

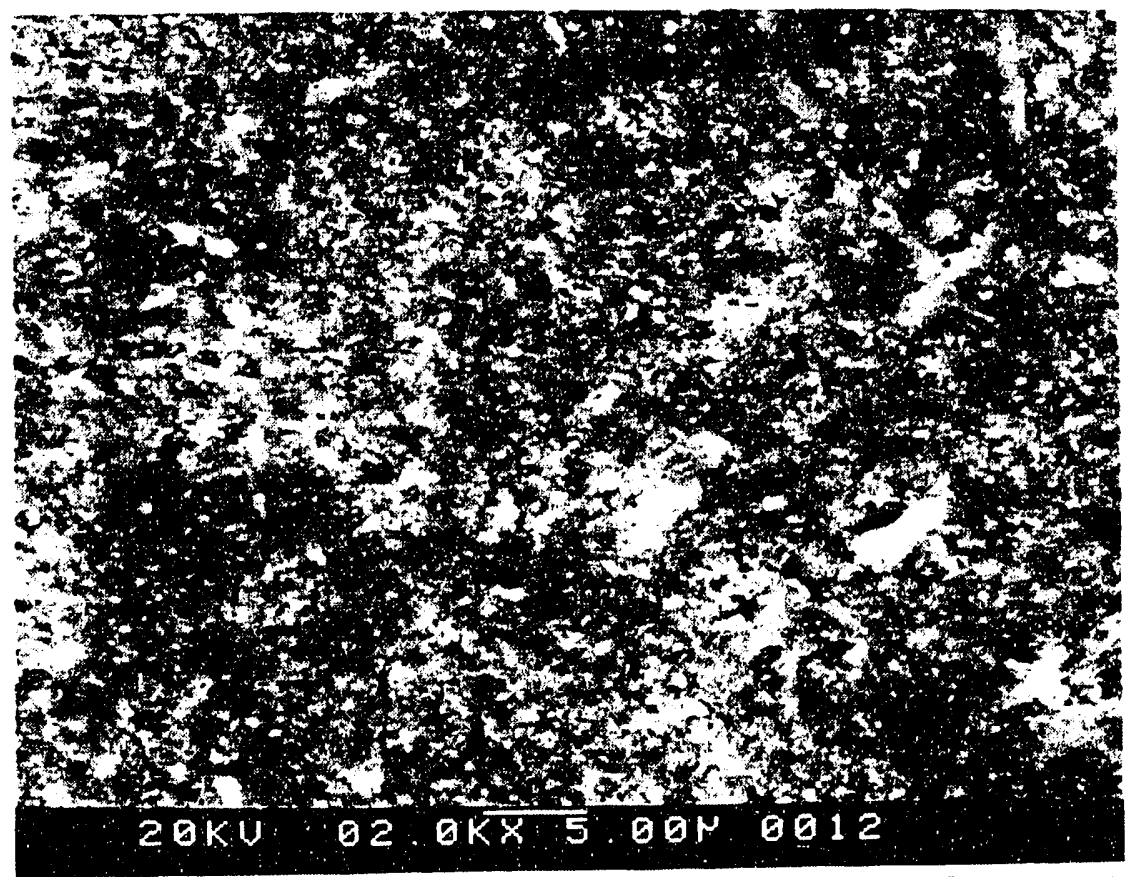

XEB 920-10036

Figure 16b. SEM micrograph of reaction ring material from the same sample. 


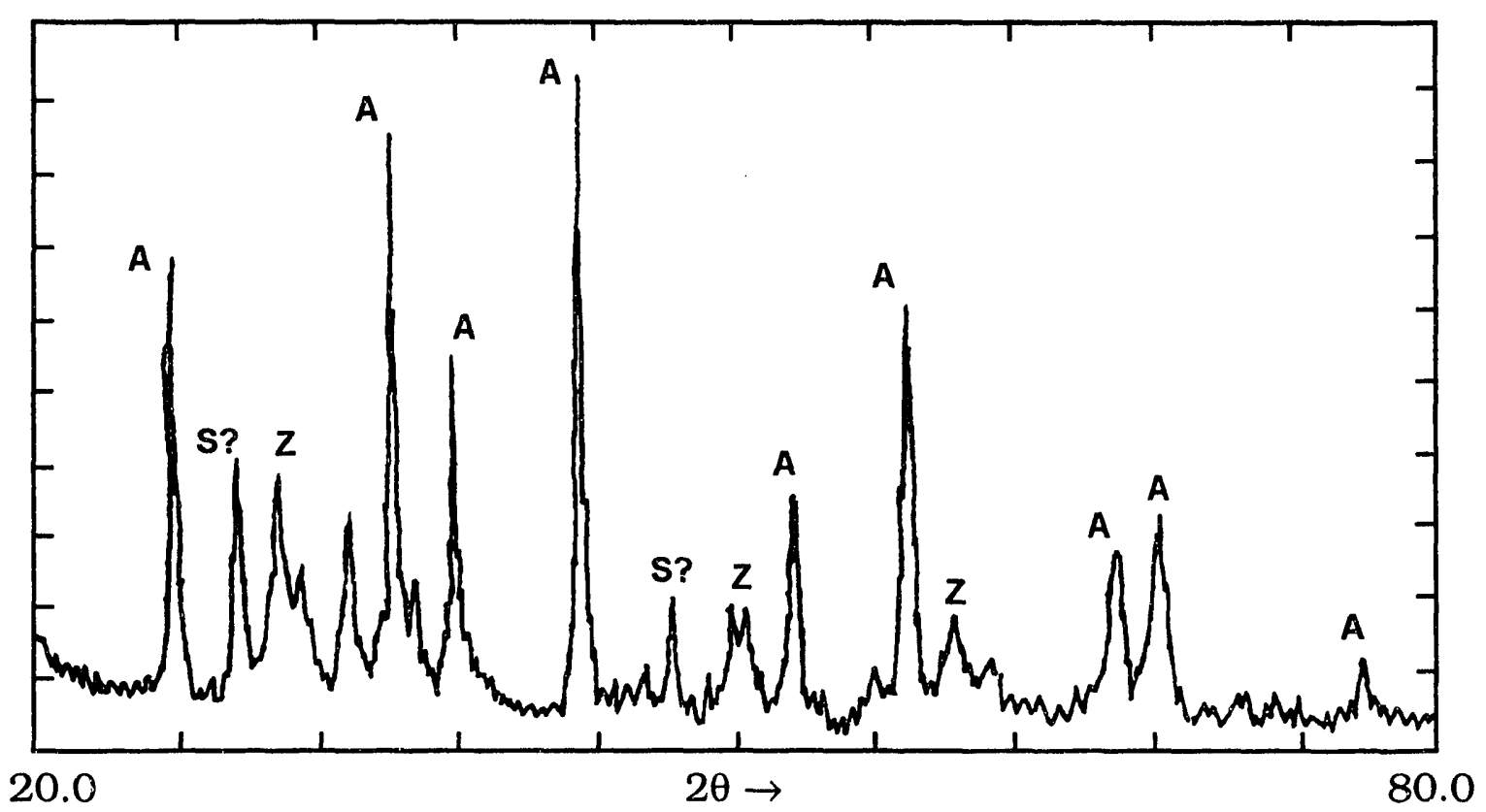

Figure 17. XRD data from core material of a sample ground in agate mortar; CIP $400 \mathrm{MPa}, 850^{\circ} \mathrm{C}$ for 7 hours. $\mathrm{A}=$ Corundum, $\mathrm{Z}=$ $\mathrm{ZrO}_{2}, \mathrm{~S} ?=$ possible $\mathrm{Si}$ peaks. 


\section{Graph of Resistivity vs. Firing Temperature}

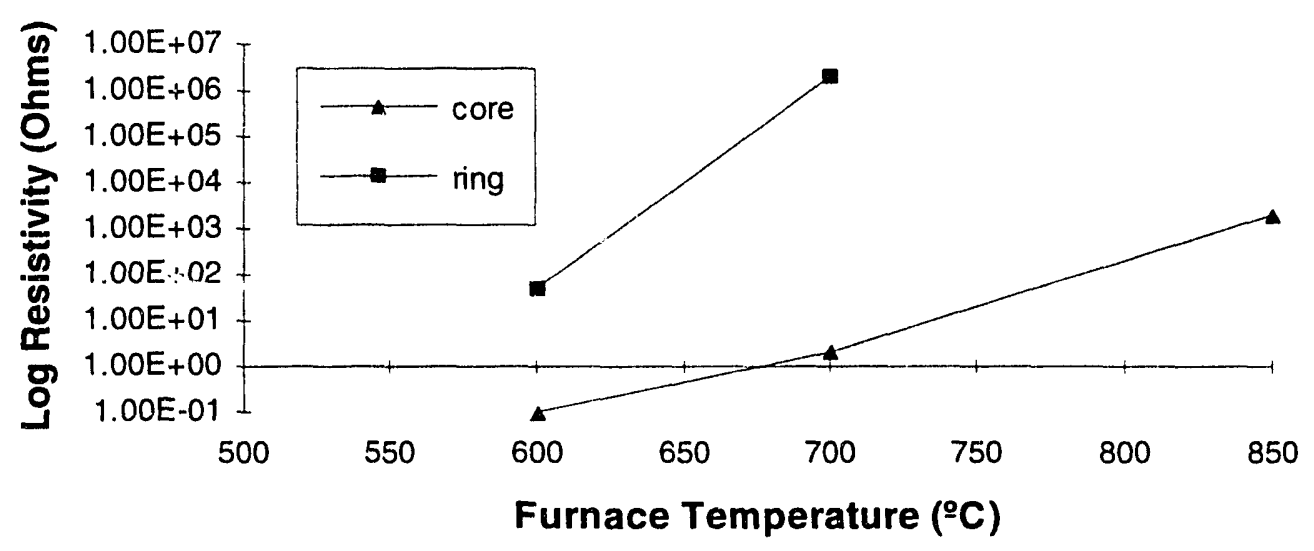

Figure 18. Graph of change in resistivity across polished sample crosssection versus firing temperature. Data taken from samples CIPed at $400 \mathrm{MPa}$ with no added $\mathrm{ZrO}_{2}$. 

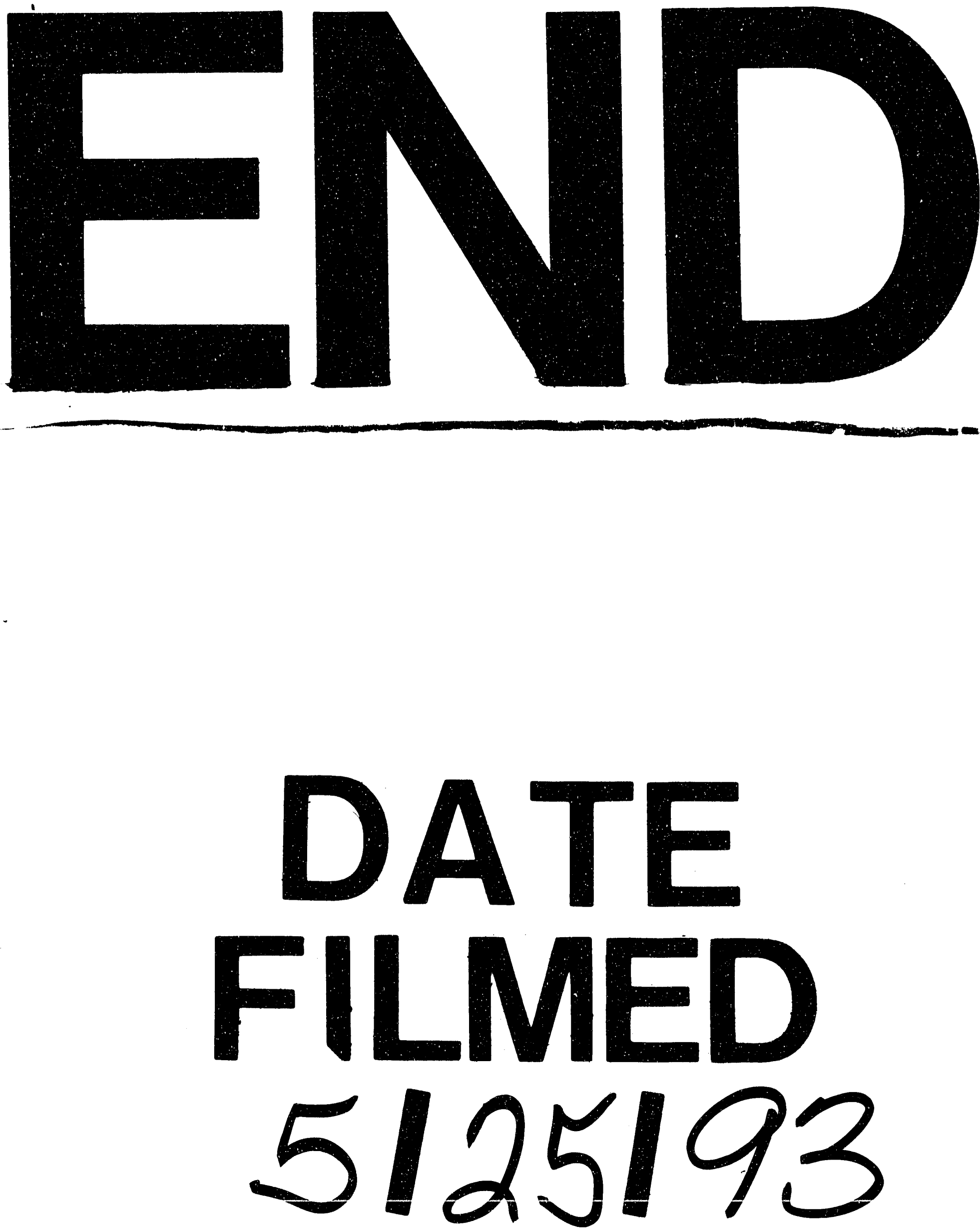
. 